\section{El Castillo de Chipiona (Cádiz)}

\section{The Castle of Chipiona (Cádiz)}

\author{
Margarita de Alba Romero* \\ Arqueóloga
}

\section{Resumen}

En este artículo presentamos una síntesis de las investigaciones arqueológicas desarrolladas en el Castillo de Chipiona (Chipiona, Cádiz) durante el año 2007 centradas fundamentalmente en el análisis paramental de sus estructuras embrionarias. La lectura estratigráfica y el estudio murario mostraron la evolución constructiva de un edificio polifásico de origen bajomedievalmoderno en uso hasta la actualidad. Aunque su tipología constructiva responde a la de un edificio defensivo tradicionalmente identificado como "Castillo» sin embargo parece responder más bien al esquema tradicional de «Torre», «Casa-Torre» o «Casa-Fuerte».

Palabras claves: estratigrafía, torre, rehabilitación monumental, medieval, tipológico, estudio de paramentos, estructuras emergentes, ostionera.

\section{Abstract \\ This work presents a synthesis of the archaeological investigations carried out in Chipiona's Castle (Chipiona, Cadiz) during the year 2007, mainly focused on the analysis of its initial structures. The stratigraphical research and the standing structures analysis show the constructive evolution of a complex medieval-modern building currently in use. Although its building typology reflects a defensive building, traditionally identified as «Castle», the archaeological remains seems to be actually a «Tower», «House-tower» or «Fort-House».}

Keywords: stratigraphy, tower, monumental rehabilitation, typological, wall analysis, standing structures, ostionera.

* margaritadealba@hotmail.com
Se aúnan en el castillo de Chipiona tradiciones verbales confusas y tópicos asentados junto al más absoluto vacío historiográfico. Nuestro análisis se postula en consecuencia como un primer acercamiento al edificio desde la más sencilla frialdad analítica. Un acercamiento basado casi en exclusiva en la estratigrafía muraria, sin apoyos en el subsuelo y por tanto reproducible o contrastable. Como resultado se presenta una secuencia de transformación en la que queda patente un origen relativamente «reciente» para su construcción y una perduración casi integral del formato original en el inmueble actual ${ }^{1}$.

\section{IDENTIFICACIÓN DEL INMUEBLE Y SU CONTEXTO HISTÓRICO-ARQUEOLÓGICO}

La villa de Chipiona está situada en el extremo Oeste del litoral atlántico gaditano frente al mar abierto y en el ángulo que hace la costa desde la bahía hacia la desembocadura del Guadalquivir. Este marco geográfico ha condicionado la formación de una plataforma litoral con bajos fondos con profundidades inferiores a los $4,5 \mathrm{~m}$, que con la piedra de la Salmedina - un arrecife que queda cubierto con la pleamar - convierte la zona en un lugar peligroso para la navegación, demostrado por los numerosos naufragios acaecidos en diferentes épocas.

Chipiona ha sido lugar de paso y continuo tránsito comercial de las distintas culturas mediterráneas desde la antigüedad. Sus primitivos habitantes se asentaron en torno a la actual roca de Salmedina bajo la denominación de Arx Gerontis, situada en el desagüe de Lacus ligustinus. Avienon a finales del siglo IV a.C. la llamó fortaleza de Gerión conquistador de los Tartessos. Con esta interpreta-

\footnotetext{
${ }^{1}$ La investigación arqueológica se enmarcaba como actividad previa dentro de proyecto de rehabilitación y puesta en valor del Castillo de Chipiona desarrollado durante los años 2007 y 2008 e inaugurado en el 2009. Los trabajos estuvieron promovidos por el Ayuntamiento de este municipio, Diputación y Junta de Andalucía, IEDT y cofinanciado por los fondos FEDER. El objetivo del proyecto era la adaptación del monumento como edificio público municipal de carácter cultural y multifuncional. Actualmente alberga el Centro de Interpretación de «Cádiz y el Nuevo Mundo». Las nuevas funciones a la que iba a ser destinado implicaban la búsqueda de espacios diáfanos lo que derivó en una afección directa de las estructuras divisorias internas y su completa eliminación, respetando en todo momento los paramentos y la organización primaria del Castillo. Este fue el principal motivo por el que el análisis arqueológico quedó limitado exclusivamente al estudio paramental de las estructuras emergentes embrionarias cuyos resultados fueron considerados en las decisiones posteriores de su puesta en valor y recuperación. Este estudio ha contado con el apoyo de un equipo intertidisciplinar coordinado por el Dr. D. Miguel Ángel Tabales (Universidad de Sevilla) y dirigido por la autora del presente artículo, integrado por profesores de la Escuela Universitaria de Arquitectura Técnica de la Universidad de Sevilla para los estudios analíticos de las fábricas edilicias, Dra. Dña. Amparo Graciani, para el análisis tipológico y Dr. D. Javier Alejandre para el análisis constructivo así como un técnico especialista ceramólogo, D. Juan Fournier.
} 


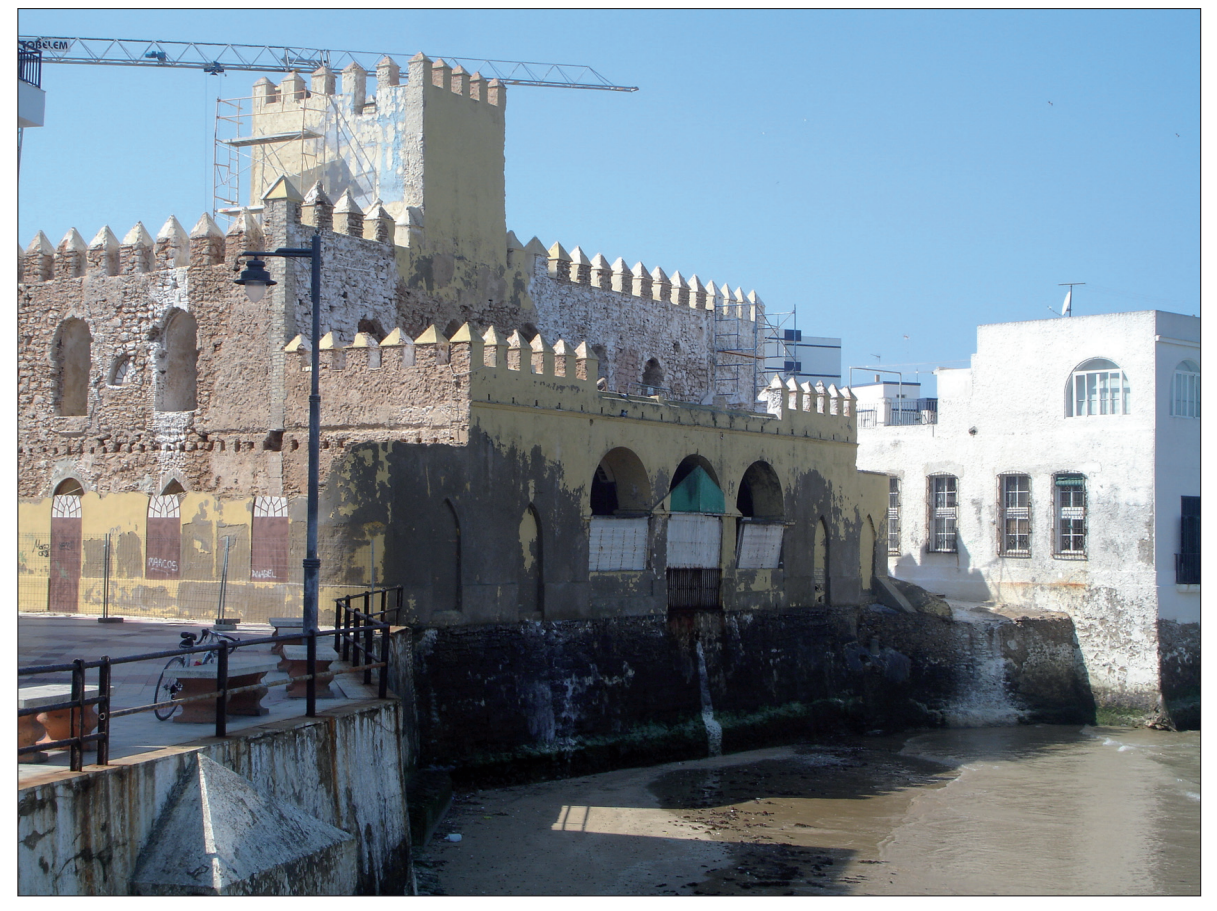

Fig. 1. Exterior del Castillo. Fachada Este y Norte. Estado previo a la rehabilitación, 2007 ción coincide Schulten" : "De igual suerte, el castillo de Gerón debe buscarse al sur del río. No cabe duda de que estuvo en el banco de Salmedina, entonces peninsula, hoy aislado y sumergido, pero que a marea baja sobresale del agua... En el banco se hallaba sin duda el faro que más tarde, en el año 139 a.C. construyó el cónsul Caepión. Y acaso la obra de ese faro fuese hecha con restos del antiguo castillo. El banco de Salmedina, que el mar rodea por todos lados, parece como hecho ex profeso para ciudadela o fortaleza marina. Se ve claramente que el castillo de Gerón tenía por objeto defender la entrada del río y el acceso a la ciudad que, como veremos, estaba poco más arriba de la desembocadura. Podemos, por lo tanto, identificar con el castillo de Gerón que los cartagineses destruyeron antes de la caida de Tartessos. Por la furia del mar, la isla Salmedina ha perdido unos dos metros de su superficie y hoy no se ve ninguna señal ni del castillo de Gerón ni del faro de Caepión».

La primera mención a la ciudad en los textos antiguos la hace Estrabón describiendo la torre que da nombre a la ciudad: Turris Caepionis. El cónsul Quinto Servilius Caepión (140-139 a.C.) construyó una especie de faro para que los navegantes que habían de entrar en el Guadalquivir pudiesen evitar los peligrosos escollos del islote de Salmedina. Estrabón la describe como»...torre de Cepión, sobre una roca ceñida por el batir del oleaje, admirablemente dispuesta, como el Faro, para auxilio de los navegantes; pues el aluvión

${ }^{2}$ Schulten, 2006: 52, 163-164. arrastrado por el río produce bajios, y la zona de la salida está tan plagada de escollos que hace falta alguna señal bien visible» $^{3}$.

Hacia el cambio de Era la zona quedaba integrada en el convento jurídico de Gades desde la creación de la Provincia Hispania Ulterior en el 27 a.C. Las poblaciones de la costa gaditana alcanzaron cierto renombre en el mundo antiguo por su vinculación al mar y en especial a la pesca y producción de conservas de salazones. Hay constancia arqueológica de unas cuatro villas romanas altoimperiales en Chipiona, dos de ellas marítimas, Las Canteras y Montijo, y otras dos interiores, La Loma y El Olivar, además de una docena de asentamientos menores propios de casas de campo. La economía se centraba en la agricultura, a pesar de que poseía núcleos de producción industrial rural característicos de los siglos altoimperiales: las canteras de piedra de molino en la Playa de las Canteras ${ }^{4}$, una factoría de salazones de pescado en el fundus maritimus de la Turris Caepionis en Regla 5 y la industria alfarera de El Olivar ${ }^{6}$, principalmente dedicada a la producción de envases anfóricos para salazones y vinos.

La dominación musulmana pasó sin mayor relevancia por la villa de Chipiona. Carecemos de documentos escritos que hagan referencia a Chipiona como asenta-

\footnotetext{
${ }^{3}$ Estrabón, 1998: 46-47.

${ }^{4}$ Ramos Millán y Riesco García, 1983.

${ }^{5}$ García Vargas, Ramos Millán, et alii, 1998: 49-62.

${ }^{6}$ Op. cit.
} 


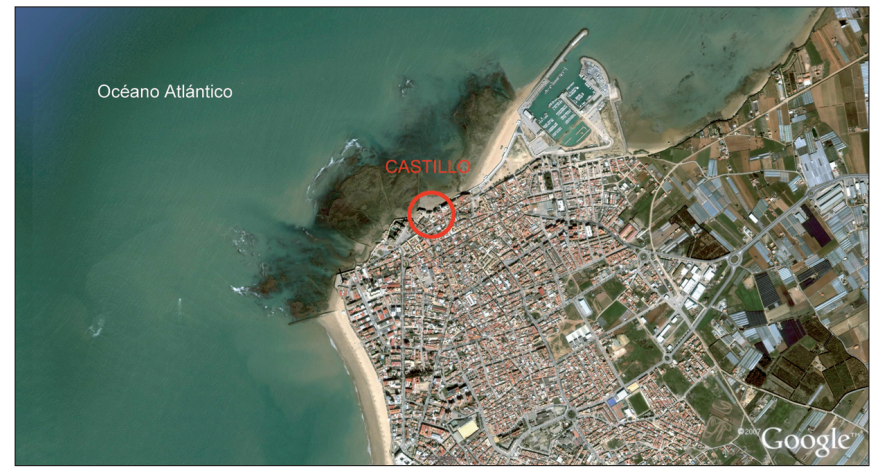

Fig. 2. Localización del Castillo en el casco urbano de Chipiona

miento urbano en el periodo hispanomusulmán. Según las fuentes tan sólo se menciona la existencia de un Castillo construido por los musulmanes pero no especifica ni donde ni si tiene algún tipo de relación con el edificio objeto de nuestro estudio ${ }^{7}$.

En 1295 Sancho IV el Bravo le cedió el señorío de Chipiona junto con otras villas de la costa entre las que se encontraban Trebujena, Rota y Sanlúcar a Don Alonso Pérez de Guzmán El Bueno por su labor de defensa contra los moros y su victoria en la guerra de Tarifa. Según las crónicas el hecho acaecido fue motivo de la construcción de una severa fortaleza o castillo en su honor ${ }^{8}$.

"tres castillos en ciertos sitios donde parescia aver avido poblasion: el uno se llamaba Rota que está sobre la mar grande poco mas de dos leguas de la isla de Caliz el otro se llamaba Regla e llamase agora Chipiona e el otro se Ilamaba Terrabuxena que agora se dice Trebuxena.»"

El empuje constructivo que se dio durante el periodo medieval no parece que afectase a la zona próxima al Castillo. Así queda demostrado en los resultados de la intervención arqueológica de las Canteras ${ }^{10}$ donde no se obtuvo ninguna información acerca de intervenciones antrópicas de naturaleza transformativa durante los siglos medievales. Solo a comienzos de la Edad Moderna se constata las primeras actuaciones en la zona. En 1490 a iniciativa de los duques de Arcos se repobló la villa con 700 familias procedentes de pueblos de Sevilla ${ }^{11}$. Para controlar tal afluencia de población se utilizó la Carta Puebla de Chipiona redactada en 1477 . La villa fue desarrollándose

\footnotetext{
${ }^{7}$ Como cita Pedro de Medina entre las mercedes de Sancho IV a Don Alonso Pérez de Guzmán, donde incluye «la tierra de la parte que los moros llamaban Chipiona, donde edificó un castillo» (Antón, 1976: 108).

${ }^{8}$ Rodríguez-Piñero, 1984: 310-312.

${ }^{9}$ Barrantes Maldonado, 1857.

${ }^{10}$ Ramos Millán y Riesco García, 1983.

${ }^{11}$ Rodríguez-Piñero, 1984: 310-312.
}

en torno al monasterio de Sta. Ma de Regla; en la Carta Puebla la villa recibe el nombre de Regla de Sta. $M^{a}$. No se menciona nada sobre el Castillo.

A partir del s. XV la bahía gaditana se convertiría en un importante puerto comercial a nivel internacional quedando Chipiona integrada en ese circuito mercantil. A finales de siglo el auge económico se trunca por la caída de las relaciones comerciales entre Cádiz y el Norte de África pasando a ser un periodo de constantes amenazas para las costas gaditanas.

Durante la Baja Edad Media y parte de la Modernidad la villa se vio afectada por el régimen señorial quedando bajo el dominio de la Casa de Arcos. Las fuentes no proporcionan datos sobre propiedades rústicas de Chipiona tan sólo se menciona el Castillo como propiedad del señor y como el lugar donde residía cuando visitaba la villa $^{12}$. Este dato no nos deja claro de cual de los dos Castillos se trata ya que el Santuario de Regla también fue considerado como tal.

En 1576 visita la villa Don Luis Bravo de Laguna enviado por el rey para supervisar el sistema defensivo de las costas occidentales de Andalucía y posteriormente realizar un proyecto de fortificaciones. El juicio emitido fue poco favorable para la infraestructura defensiva de Chipiona, describiendo a la torre de Regla como «pequeña y muy ruin, sin ninguna torre», a pesar de ello considera positiva la defensa de los bastimentos y la guarnición ${ }^{13}$. Esta descripción tampoco aclara de cual de las construcciones defensivas se trata al mencionar a la Torre de Regla como torre, pero no como Santuario y en ningún caso hacer alusión al Castillo.

Durante el s. XVII se sucedieron numerosos intentos fallidos de invasión inglesa en las costas gaditanas. No sería hasta 1702 con la Guerra de Sucesión cuando las tropas anglo-holandesas consiguieron por fin desembarcar en Chipiona bajo mandato del príncipe Jorge de Darmstadt motivado por la fidelidad que tenía Chipiona a Felipe $\mathrm{V}^{14}$.

En 1755 la villa fue duramente castigada por el terremoto de Lisboa. Este hecho queda recogido en el lienzo de la Ermita del Cristo de las Misericordias donde se representa el Castillo abatido por el oleaje del maremoto (Fig. 4).

Según el lienzo existente en la Ermita del Cristo de las Misericordias, adosado al muro que enfrenta al mar tenía un pequeño fortín y en él estaba la entrada al edificio. Contaba también al exterior con una plaza de armas y ejido y al otro lado se hallaba también la batería.

\footnotetext{
12 Ruano, 1985: 49.

${ }^{13}$ Antón, 1976: 109.

${ }^{14}$ Rodríguez-Piñero, 1984: 310-312.
} 

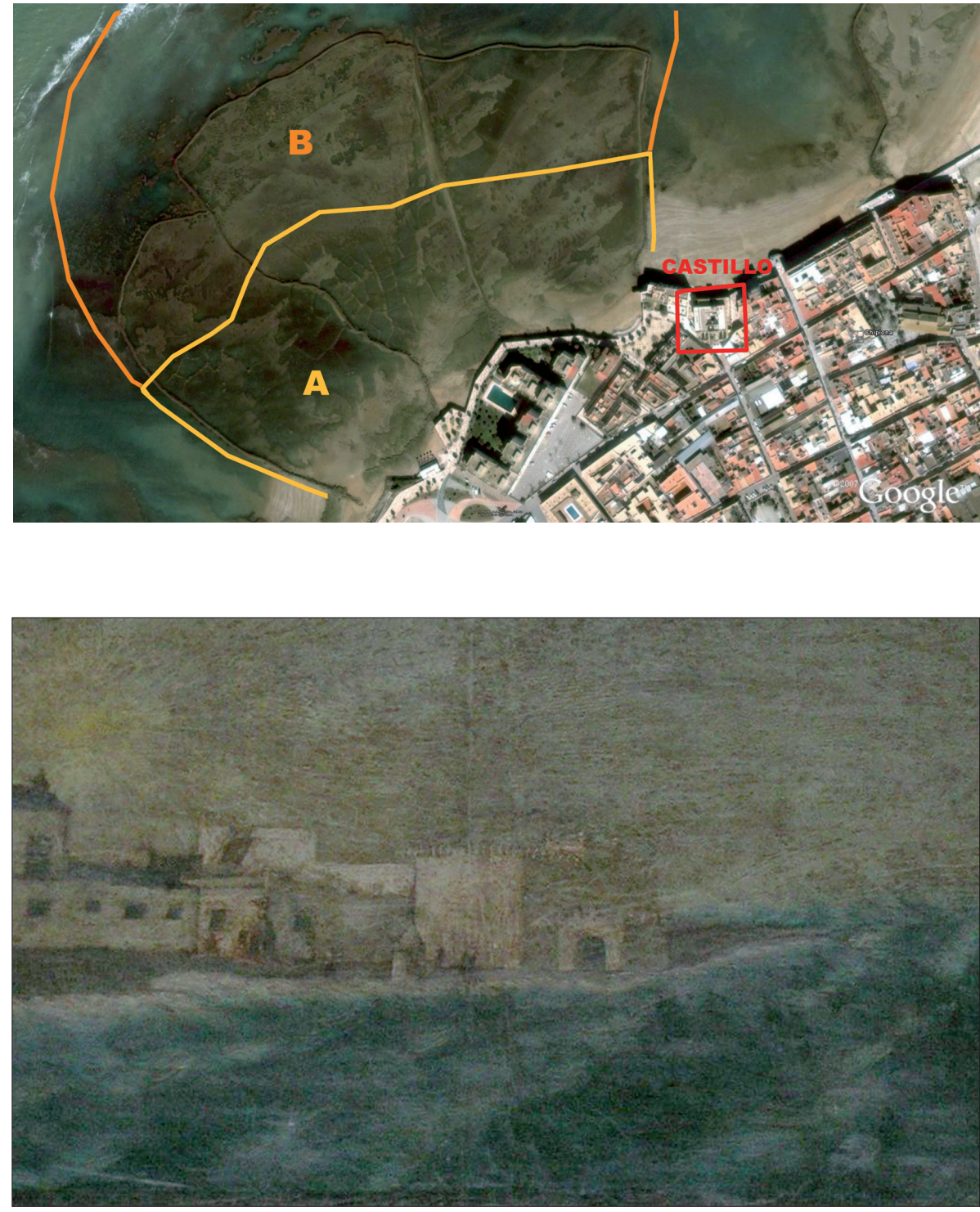

Fig. 3. Transformación del arrecife ${ }^{15}$ : A. Tramo costero: 50-200 m. desde la línea litoral actual. Estructuras de explotación cuadriláteras, correspondiente a actividades de cantería medievales, modernas y sobre todo contemporáneas. B. Desde $200 \mathrm{~m}$. del talud litoral a mar adentro: tramo con explotación de estructuras circulares, con escasas estructuras cuadradas. Tramo de explotación romana
Fig. 4. Cuadro de la Ermita del Cristo de la Misericordia (Chipiona) con la representación del Castillo en el centro de la imagen
Durante el s. XIX Chipiona se convirtió en un importante enclave turístico para las clases adineradas teniendo su antecedente más notable en los duques de Montpensier que hicieron de Chipiona localidad de veraneo y balneario de la aristocracia. Fue en estos momentos cuando el Castillo modifica su fisonomía adaptándose al último uso que tuvo: el hotelero.

El inmueble declarado BIC se ubica en el casco histórico de Chipiona, al Norte de la localidad, frente al mar abierto y en el ángulo que hace la costa desde la bahía hacia la desembocadura del Guadalquivir. Está emplazado en primera línea de playa asentado sobre la muralla que cubre el antiguo acantilado de la zona que va desde la Cruz del mar hacia las Canteras (Figs. 1 y 2).

La construcción medieval se organiza en torno a un patio central con aljibe que distribuye al edificio en dos plantas con cuatro crujías perimetrales. Se trata de un edificio aislado en sus cuatro frentes, presenta planta cuadrada con una torre de la misma forma en la fachada Norte.

Su base era un cuadrado de 87 metros y 473 de superficie.

Tradicionalmente se pensaba que el edificio estaba construido sobre una plataforma de roca natural, la misma que aparece en el litoral costero donde se encuentran los «Corrales», pero tras los estudios arqueológicos se pudo constatar cómo los muros maestros se levantaban sobre las arenas rojizas del litoral marino. El edificio queda protegido de las batidas del mar gracias a la plataforma de sillarejos de piedra ostionera construida en su fachada Norte (Fig. 1).

\footnotetext{
${ }^{15}$ Ramos Millán y Riesco García, 1983.
} 


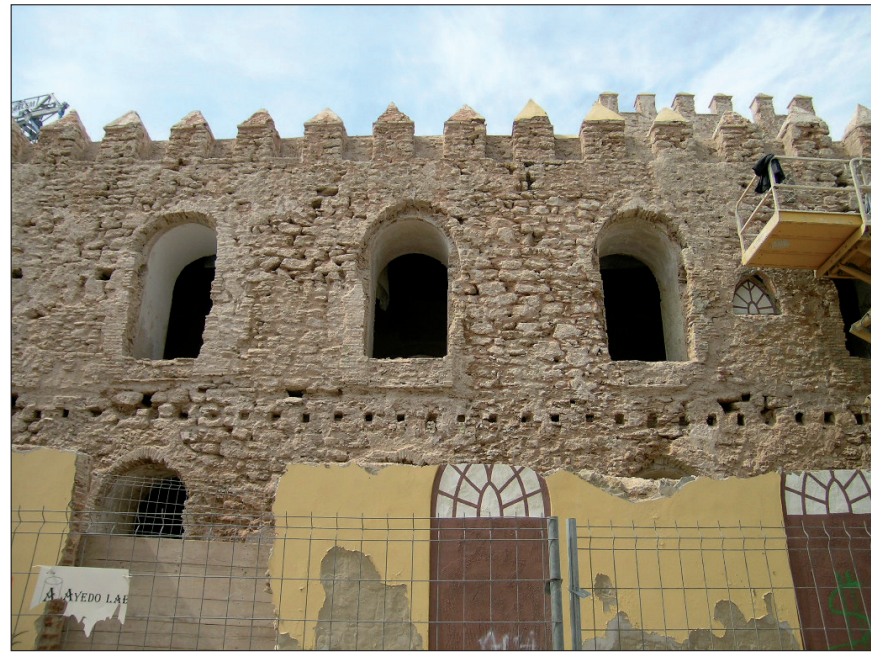

Fig. 5. Fachada Este. Exterior del edificio con paramentos desprovistos del enfoscado contemporáneo

\section{ANÁLISIS ARQUEOLÓGICO}

El estudio arqueológico ha esclarecido en gran medida la evolución cronocultural, tipología constructiva, formal y el estado de conservación del edificio. De la misma manera que se resolvieron algunos de los objetivos planteados quedaron abiertos otros frentes que no pudieron ser definidos en la intervención por estar limitada exclusivamente al análisis paramental de las estructuras primarias. Uno de ellos fue la adscripción cronológica del momento fundacional del Castillo. La carencia de sondeos arqueológicos imposibilitó definir tanto cronológica como formalmente el edificio originario, por tanto cabe decir que los resultados dados se exponen con todas las reservas que ello conlleva ya que el estudio paramental desarrollado carece de un apoyo cronológico determinante aportado por el material cerámico de su cimentación con el que corroborar la fecha de construcción planteada.

Para la toma de datos se siguió un sistema de trabajo basado en el planteamiento teórico aplicable a cualquier tipo de investigación arqueológica sobre inmuebles Históricos en proceso de Rehabilitación ${ }^{16}$, fundamentada principalmente en las ópticas estratigráficas y tipológicas apoyadas por las analíticas constructivas y ceramológicas.

\section{SECUENCIA ESTRATIGRÁFICA}

La carencia de sondeos arqueológicos nos hace ser cautos en la propuesta cronológica dada para cada Actividad, especialmente en las actividades constructivas I y II. En

${ }^{16}$ Sistema de análisis arqueológico de edificios históricos propuesto por M. Á. Tabales.
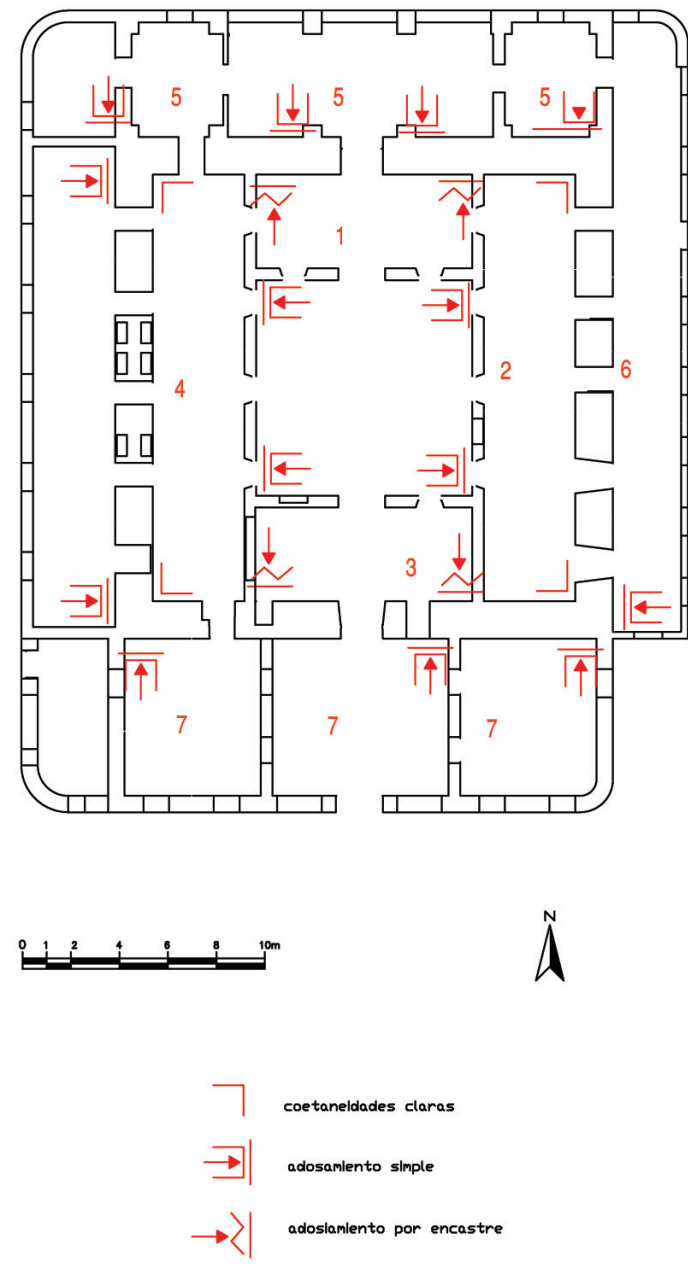

Fig. 6. Sistemas de adosamiento y contacto entre muros principales

este sentido queremos poner de manifiesto que una vez realizado el estudio paramental los lugares elegidos para realizar futuras catas serían zonas muy puntuales, cuyos resultados con toda probabilidad resolverían la problemática ya señalada. Por ello ante la privación de la información subyacente nos hemos basado en otras premisas a través de las cuales planteamos nuestra propuesta cronológica y formal:

- Funcionamiento estratigráfico del edificio: relación anteroposterioridad de los elementos estudiados.

- Tipología formal del edificio: el Castillo (Actividad I) responde al modelo de Castillo/Casa-fuerte desarrollado a partir del s. XV sobre todo en el Norte de España. Se trata de edificios de planta cuadrangular con forma achatada, no superando en altura su perímetro. Suelen tener pocos vanos y apenas motivos decorativos. Son «castillos» defendidos por sí mismos, sin murallas ni torres adosadas, siendo su única defensa los gruesos muros perimetrales y en ocasiones una torre, generalmente centrada. 


\begin{tabular}{|c|c|c|}
\hline \multicolumn{2}{|c|}{ FÁBRICAS } & \multirow{3}{*}{ Castillo } \\
\hline Tipo 1 & $\begin{array}{l}\text { ALINEADO SUBHORIZONTAL IRREGULAR DE MAM PUESTOS, } \\
\text { con o sin relleno de esquirlas }\end{array}$ & \\
\hline & $\begin{array}{l}\text { Dimensiones medias del mampuesto: } 20-45 \mathrm{~cm} \\
\text { Mortero: arena v cal }\end{array}$ & \\
\hline \multirow[t]{2}{*}{ Tipo 2} & $\begin{array}{l}\text { IRREGULAR SIN ALINEAMIENTO DE MAMPUESTOS } \\
\text { PEQUEÑOS }\end{array}$ & \multirow{2}{*}{$\begin{array}{l}\text { Muros longitudinales en } \\
\text { planta baja rodeando el } \\
\text { patio }\end{array}$} \\
\hline & $\begin{array}{l}\text { Dimensiones del mampuesto: } 10-20 \mathrm{~cm} \\
\text { Mortero: arena v cal }\end{array}$ & \\
\hline \multirow[t]{2}{*}{ Tipo 3} & HILADAS DE LADRILLO SEPARANDO SILLAREJOS & \multirow[b]{2}{*}{ Mirador al Mar } \\
\hline & $\begin{array}{l}\text { Dimensiones del ladrillo: } 27 \times 13 \times 2,5 / 3 \mathrm{~cm} \\
\text { Dimensiones máximas sillarejos: } 45 \times 20 \mathrm{~cm} \text {. } \\
\text { Llagas: } 2 \mathrm{~cm} \text {. } \\
\text { Listel: } 0,5 / 1 \mathrm{~cm} \text {. } \\
\text { Mortero: arena v cal }\end{array}$ & \\
\hline \multirow[t]{2}{*}{ Tipo 4} & LÍNEAS DE LADRILLOS Y MAMPUESTOS PEQUEÑOS & \multirow[b]{2}{*}{$\begin{array}{l}\text { Muros del interior y } \\
\text { Estructuras que } \\
\text { envuelven la } \\
\text { Casa-fuerte }\end{array}$} \\
\hline & $\begin{array}{l}\text { Dimensiones del lad rillo: } 27 \times 13 \times 2,5 / 3 \mathrm{~cm} \\
\text { Dimensiones del mampuesto: } 15-30 \mathrm{~cm} \\
\text { Llagas: } 2 \mathrm{~cm} . \\
\text { Listel: } 0,5 / 1 \mathrm{~cm} . \\
\text { Mortero: arena v cal }\end{array}$ & \\
\hline
\end{tabular}
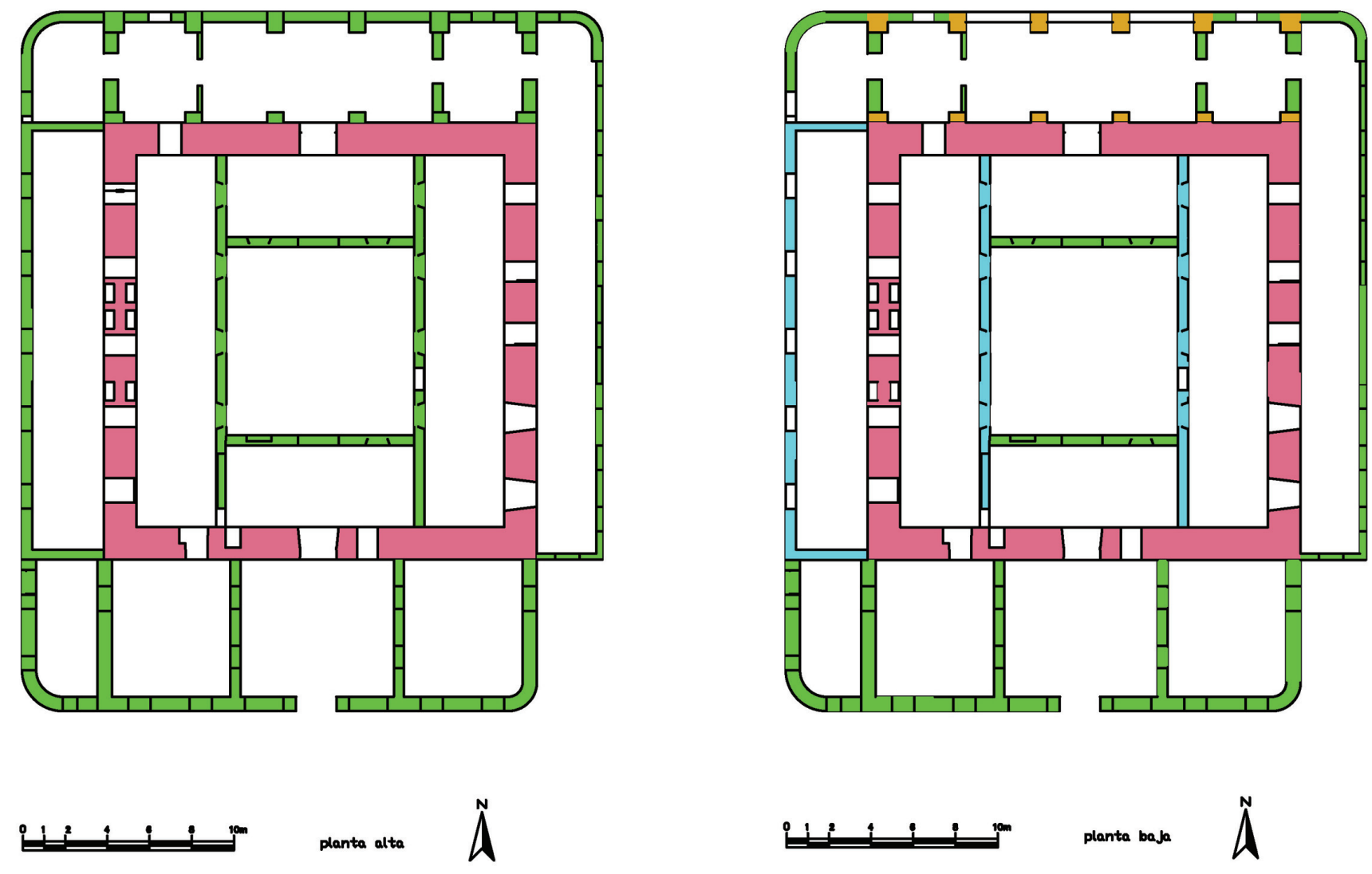

Fig. 7. Análisis edilicio 

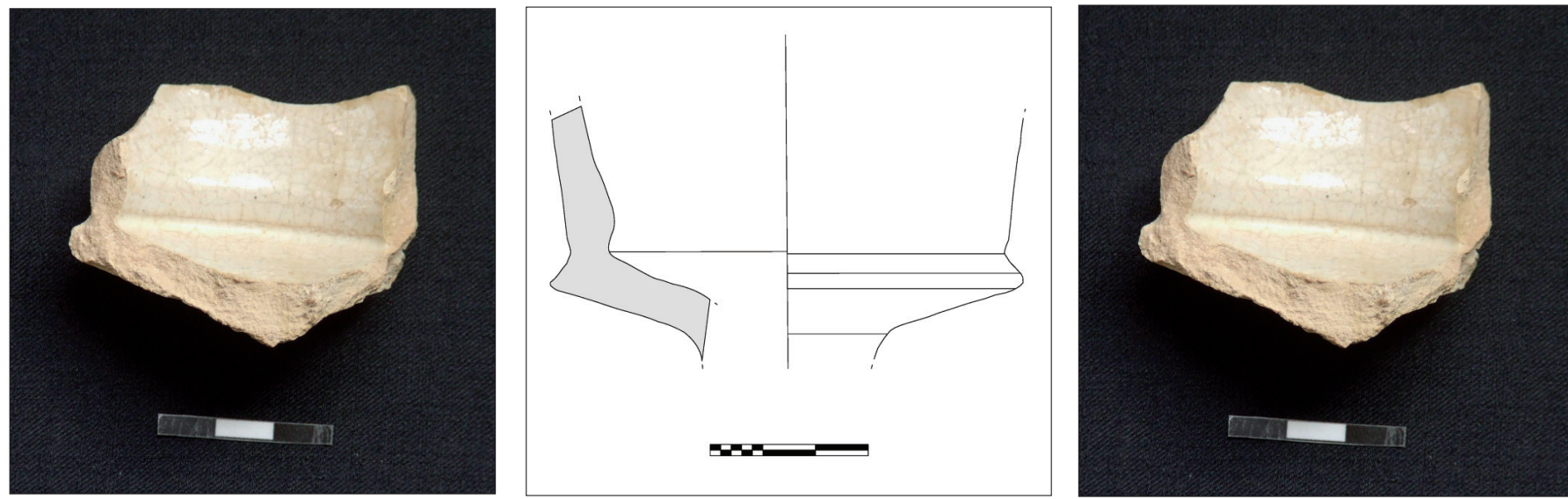

Fig. 8. Pieza cerámica extraída del mechinal

No eximimos en ningún momento la identificación del Castillo de Chipiona como tal ni mucho menos su carácter defensivo, pero siguiendo los modelos de la poliorcética podemos aproximarnos a la tipología descrita.

- Tras el reconocimiento de todos aquellos mechinales accesibles pudimos recoger el material del interior de los muros embrionarios. Tan sólo en uno de ellos se localizó un fragmento cerámico (Fig. 8). Esta escasa, pero valiosa prueba correspondía a un mechinal de la planta baja de uno de los muros del castillo. Este mechinal estaba cegado, como la gran mayoría, con mampuestos. El fragmento cerámico se encontraba a gran profundidad, aproximadamente en la zona central del ancho del muro, junto con rellenos de arena y esquirlas de piedra. Con toda probabilidad este fragmento debió ser colocado allí durante la puesta en obra del castillo. La cronología de dicha pieza pertenece al siglo XV, generalizada en su segunda mitad y pudiendo alcanzar hasta el primer tercio del siglo $\mathrm{XVI}^{17}$.

- En ninguno de los casos se ha localizado material cerámico de cronología ante quem a la pieza mencionada.

- Sabemos que hay un proceso constructivo posterior a la construcción del castillo y anterior a la construcción del hotel. Se trata de una reestructuración espacial del edificio embrionario, tanto del interior como del exterior. Este hecho queda recogido en las fuentes escritas donde se mencionan los distintos usos y moradores que tuvo a lo largo de la Modernidad, llevando consigo una serie de «reconstrucciones». Esta fase la hemos identificado con la Actividad II. De nuevo ante la carencia de material

\footnotetext{
${ }^{17}$ Se trata de un galbo de pastas rosáceas con acabado de cobertura estannífera por ambas caras. No presenta decoración, por lo que plausiblemente se encuadre dentro de la serie Blanca lisa de tradición mudéjar. Probablemente se trate de un pitcher o jarro con pie moldurado o liso y pico o pitorro vertedor o de una jarra con pie moldurado. Estudio cerámico realizado por J. Fournier.
}

cerámico y la inexistencia de elementos significativos que nos aporten una información cronológica más precisa esta segunda actividad la encuadramos dentro de un arco cronológico más amplio que iría desde el s. XVI hasta el s. XVIII rigiéndonos por la relación de anteroposterioridad.

\section{Actividad I. Castillo.}

Muros perimetrales de la primera construcción sobre los que se acoplan todas las estructuras posteriores. Conserva una altura de 7,75 m hasta la línea de adarve sobre el que va situado el parapeto y el almenado (Fig. 11). Las dimensiones de las estancias actuales son el resultado de reformas posteriores. En este primer momento poseería una sola altura y una división interna diferente, configurando un edificio de una planta con un nivel de suelo semejante a la cota actual y naves longitudinales más anchas que las presentes. Las cuatro salas perimetrales abrazaban un espacio central. Estas naves quedaban iluminadas por dos vanos situados en los frentes Norte y Sur (Figs. 9 y 10). Se trata de ventanas con arcos apuntados abocinados al interior, formados con dovelas de mampuestos de $0,30 \mathrm{~m}$. Ocupan la zona central del alzado estando la clave a unos $6 \mathrm{~m}$ sobre rasante. Las ventanas están situadas a tres metros de separación del muro medianero.

Suponiendo que la disposición original de estos vanos fuese centralizada en relación con los frentes de las naves longitudinales, si extrapolamos la medida que separa el vano del muro lateral del Castillo nos quedaría una estancia de $7 \mathrm{~m}$ de luz. Estas troneras fueron anuladas tras las reformas modernas con la incorporación del nuevo forjado y las paredes longitudinales haciendo incompatible dichos elementos (Fig. 10).

Los cuatro muros conservados del Castillo poseen idéntica factura. Son muros de 1,55 m de espesor homogé- 


\begin{tabular}{|c|c|c|c|}
\hline & ACTIVIDADES & CRONOLOGIAA & IDENTIFICACIÓN \\
\hline & I & S. XV & Castillo \\
\hline & II & s. XVI-XVIII & Rehabilitación y nueva distribución de los espacios \\
\hline & III & $\begin{array}{c}\text { s. XIX } \\
\text { (Ca. 1886) }\end{array}$ & Construcción del hotel \\
\hline & IV & $\begin{array}{l}\text { S. XX } \\
\text { (1) }\end{array}$ & Reparaciones y subida de forjados \\
\hline & V & $\begin{array}{l}\text { s. XX } \\
(2)\end{array}$ & Reparaciones contem poráneas del hotel \\
\hline & VI & 2007 & Obra de rehabilitación actual \\
\hline
\end{tabular}

Tabla 1. Secuencia estratigráfica

neo en todo su alzado. Su fábrica destaca por su solidez y robustez frente al resto de estructuras adosadas a posteriori que presentan una fábrica de menor calidad (Figs. 7 y 14). El material empleado en su construcción es básicamente la piedra ostionera. Emplean una técnica constructiva simple con mampuestos irregulares de gran tamaño tendente a la horizontalidad, trabados con mortero de arena $\mathrm{y} \mathrm{cal}^{18}$. Las dimensiones medias de estos mampuestos son de $0,45 \times$ $0,20 \mathrm{~m}$ acoplados unos con otros y regularizados con esquirlas colocadas durante la puesta en obra. Las caras exteriores del muro están bien trabadas con un mortero consistente de cal. La construcción del muro se hizo con un sistema de andamiaje empotrados o en voladizo sobre parales quedando la huella de los mechinales en todos los paramentos. La fábrica quedaba protegida con un revestimiento de mortero de cal teniendo mayor resistencia y volumen los paramentos exteriores.

El control de movimiento de tierras ha permitido identificar la cimentación del muro Sur (Fig. 16). Está construido sobre una zapata de cimentación corrida con un escalón que sobresalte de 0,20 $\mathrm{m}$ y una profundidad de $0,62 \mathrm{~m}$. La base queda reforzada por una torta de arena

\footnotetext{
18 Análisis de los morteros realizado por el D. J. Alejandre. Se trata de un mortero de cal de buena calidad y compacto, con porosidad baja. Está constituido principalmente por cuarzo y carbonato de calcio, con una dosificación menor o igual a la de 1:3 (de cal / arena), no presenta aditivo de yeso. A su vez contiene, de forma minoritaria, sales que pueden provenir bien de la arena empleada o bien por humedades de capilaridad y que en un futuro podría provocar la formación de eflorescencias.
}

enriquecida con cal de $0,10 \mathrm{~m}$ de espesor y $0,75 \mathrm{~m}$ de ancho que a su vez apoya sobre una capa de tierra mejorada. La zapata del muro, al igual que éste, está construida con mampuestos de piedra ostionera trabados con mortero de cal. El terreno sobre el que se asienta la cimentación está constituido por arenas de color rojizo, limpias y homogéneas, sin presencia de material arqueológico alguno. Esta capa de arena rojiza aparece también en

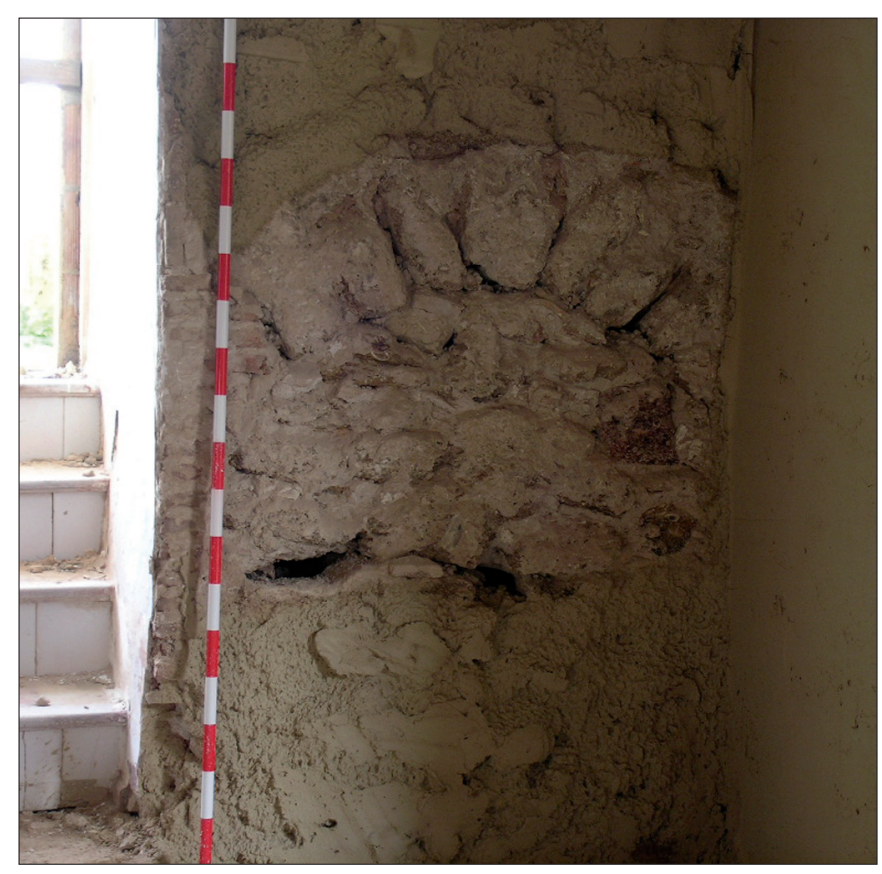

Fig. 9. Vano primitivo cegado en muro Sur. Amortizado por la incorporación del muro e incompatible con el nivel del suelo de la primera planta 


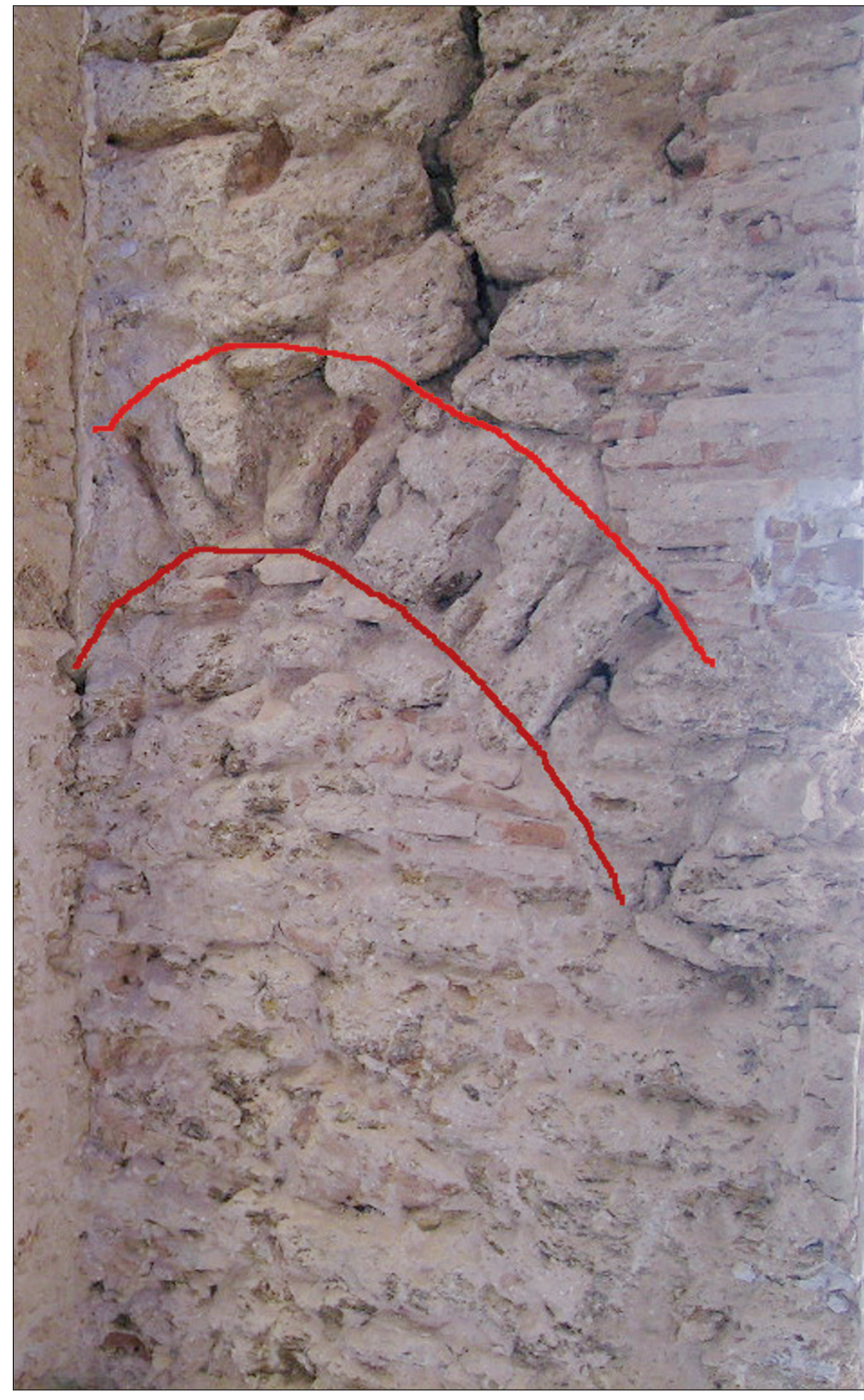

Fig. 10. Vano primitivo cegado en muro Norte

el corte del ascensor cubriendo al sillar localizado en uno de los perfiles. La zapata se encuentra a 0,10 mts. bajo la cota del suelo actual, lo que nos indica que la cota de uso del edificio primigenio debería de ser igual o superior a la que vemos hoy.

En ninguno de los muros han aparecido huellas de forjado a media altura que marquen la existencia en origen de una segunda planta. No aparece ningún elemento asociado a las cubiertas primitivas, como resaltes o molduras que indiquen la presencia en ese lugar de un sistema de cerramiento determinado, por lo que la solución empleada debería de aprovechar parte del paso de ronda donde descansarían los cabos de viga. Los paramentos interiores tampoco muestran ningún indicio de encastre o adosamiento de muros transversales que dividiesen el interior de la Casa, como ocurre actualmente, haciéndose necesaria la existencia de una estructura central que soportase las

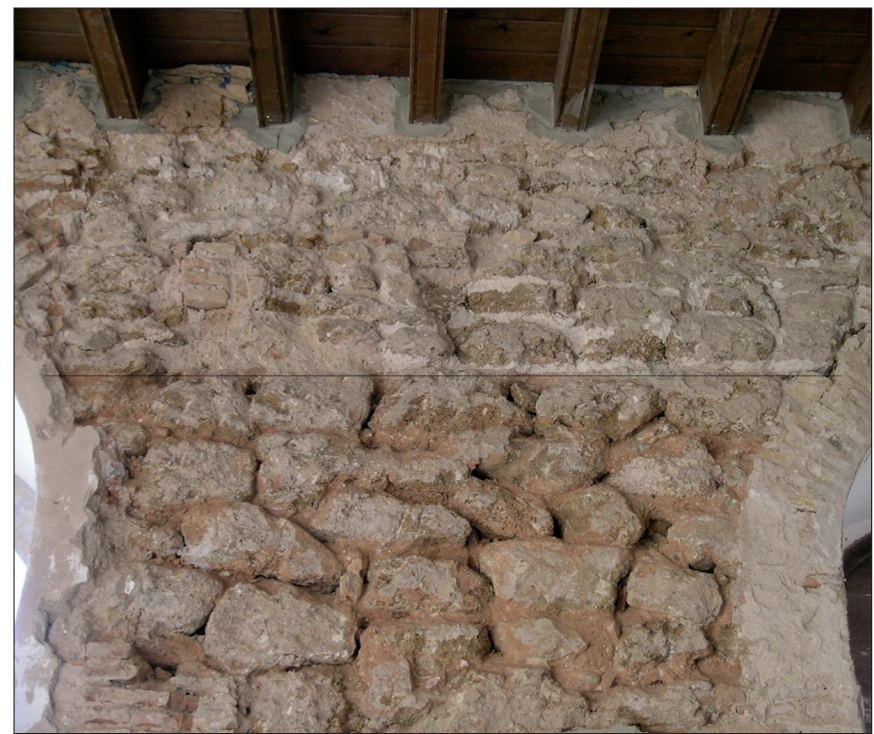

Fig. 11. Muro Sur, planta alta. Zona de adarve recrecida con mampuestos de tamaño menor

cubiertas originales y a su vez distribuyera los espacios. Los muros estudiados tampoco han evidenciado la huella de escaleras u otro elemento que sirviese de acceso hacia la zona superior.

Según las fuentes y un lienzo conservado en una ermita cercana al Castillo (Fig. 3) en el frente Norte se encontraba la única puerta de acceso al edificio que quedaba protegida por un revellín adelantado. Tras el estudio paramental no se han detectado huellas de encastre o contacto que delaten la presencia de esta teórica estructura acoplada a la fachada, situada según el cuadro en la zona central del muro Norte (Figs. 13 y 26). De la portada original tampoco queda rastro alguno solamente la continuidad de su uso como zona de acceso; al no haberse

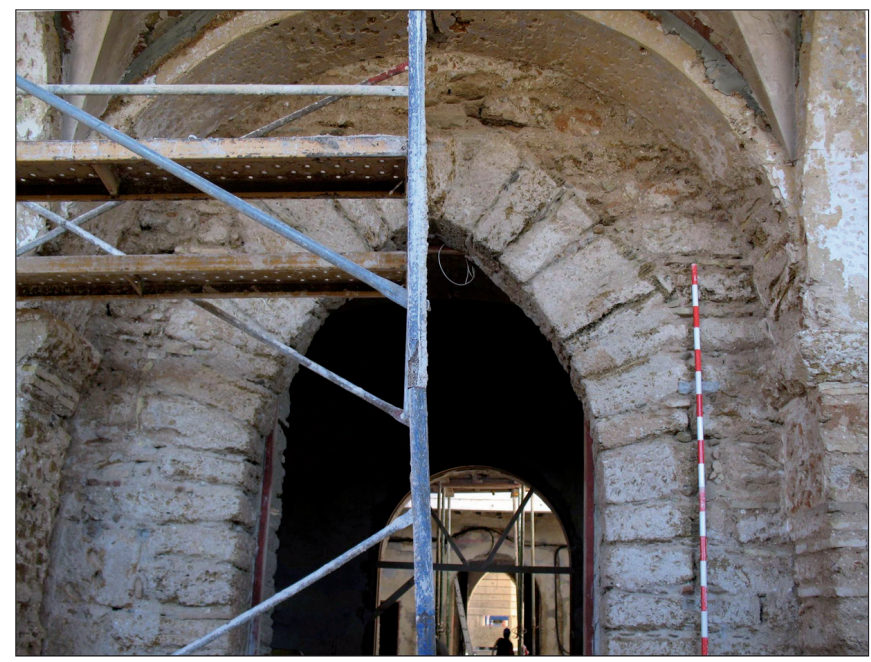

Fig. 12. Puerta de acceso principal al Castillo desde el mirador. Posible ubicación de la puerta original 

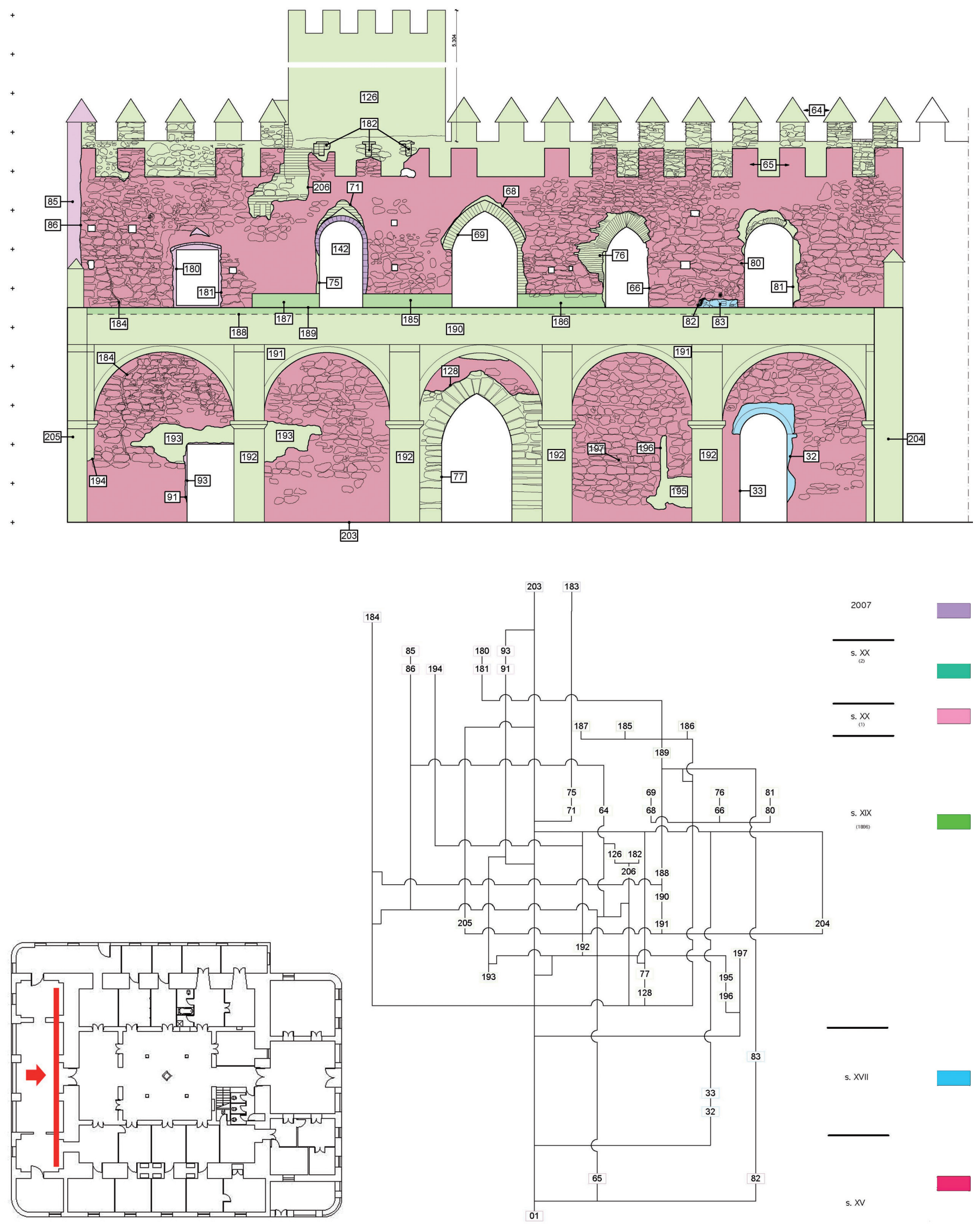

Fig. 13. Estancia 5, alzado Sur. Análisis estratigráfico 


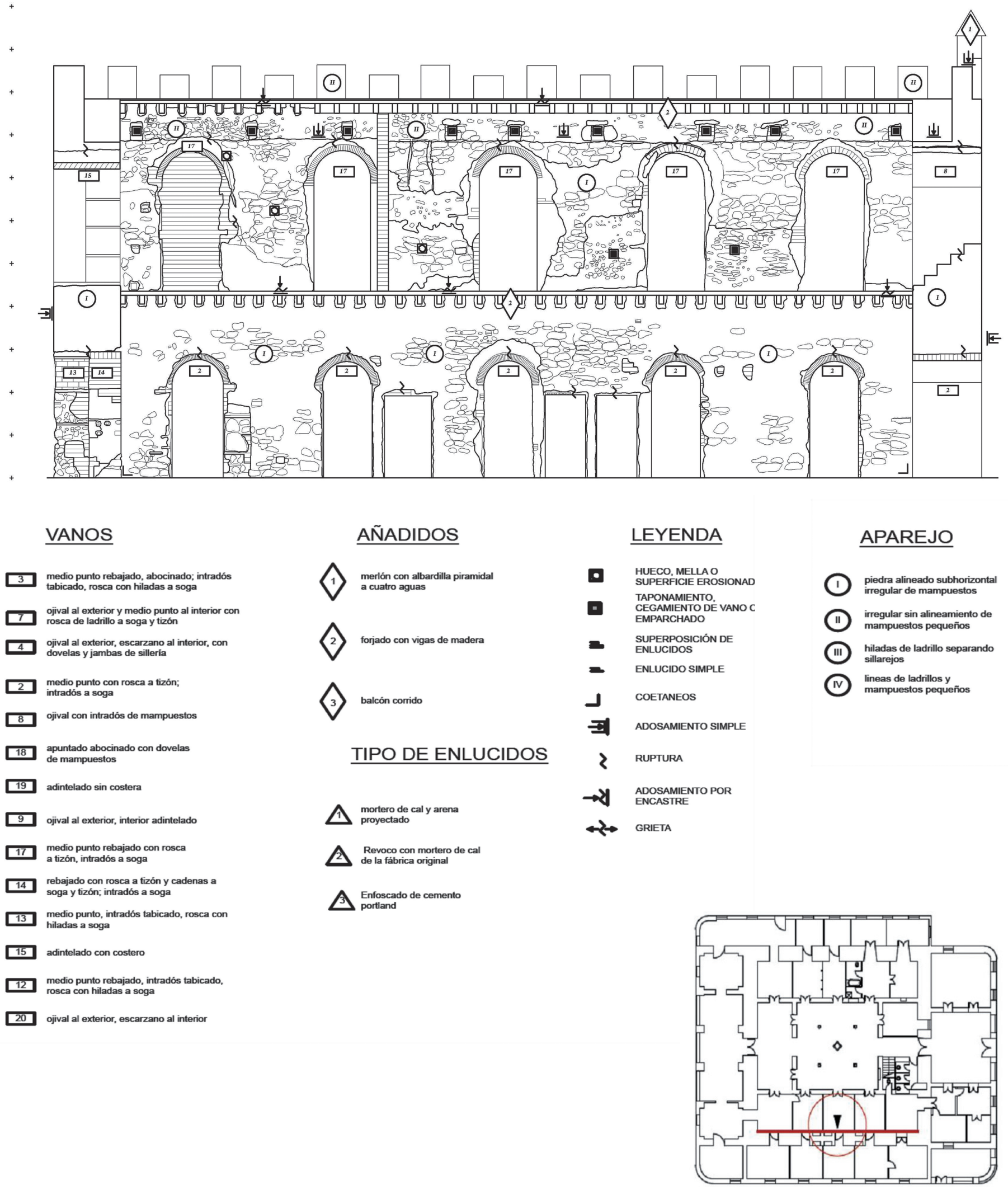

Fig. 14. Estancia 4, alzado Oeste. Análisis constructivo y tipológico El espacio vertical también sufriría modificaciones. Se dividió la altura del edificio en dos plantas a una cota sobre superficie de 4,40 m, esta altura coincide con la actual. El nuevo forjado se encastra sobre los muros del castillo anulando los vanos originales. Las cubiertas continuarían a la misma cota, pero dispuestas de manera diferente, apoyando sobre los nuevos muros y los muros transversales a estos dos. La incorporación de este nuevo forjado supuso la amortización del adarve, ya que para que las vigas tuviesen una buena sujeción se recreció todo el paseo de ronda hasta la altura de las almenas. Las cajas de viga están situadas directamente sobre la línea de adarve quedando protegidas con mampuestos de mayor tamaño 


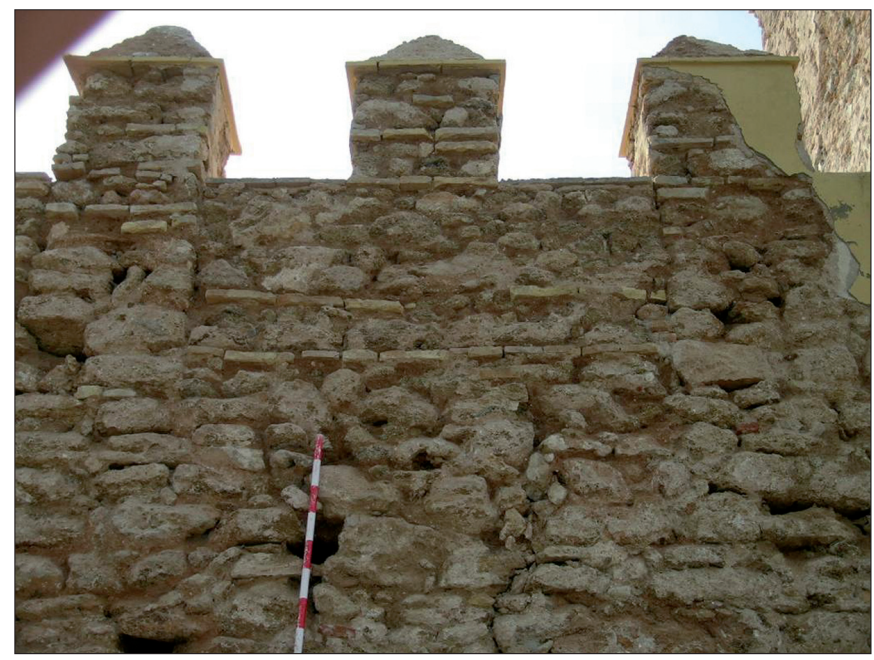

Fig. 15. Línea de almenas interrumpida por la pérdida de uno de los merlones originales y cegado con el recrecido contemporáneo

localizado en ningún otro lugar creemos que la puerta de entrada al edificio primitivo debería ubicarse aquí en el centro del muro meridional, sustituida en el s. XIX por la portada monumental que vemos hoy (Fig. 12).

Los cuatro muros perimetrales quedaban coronados por una línea de almenas de forma rectangular simple, sin

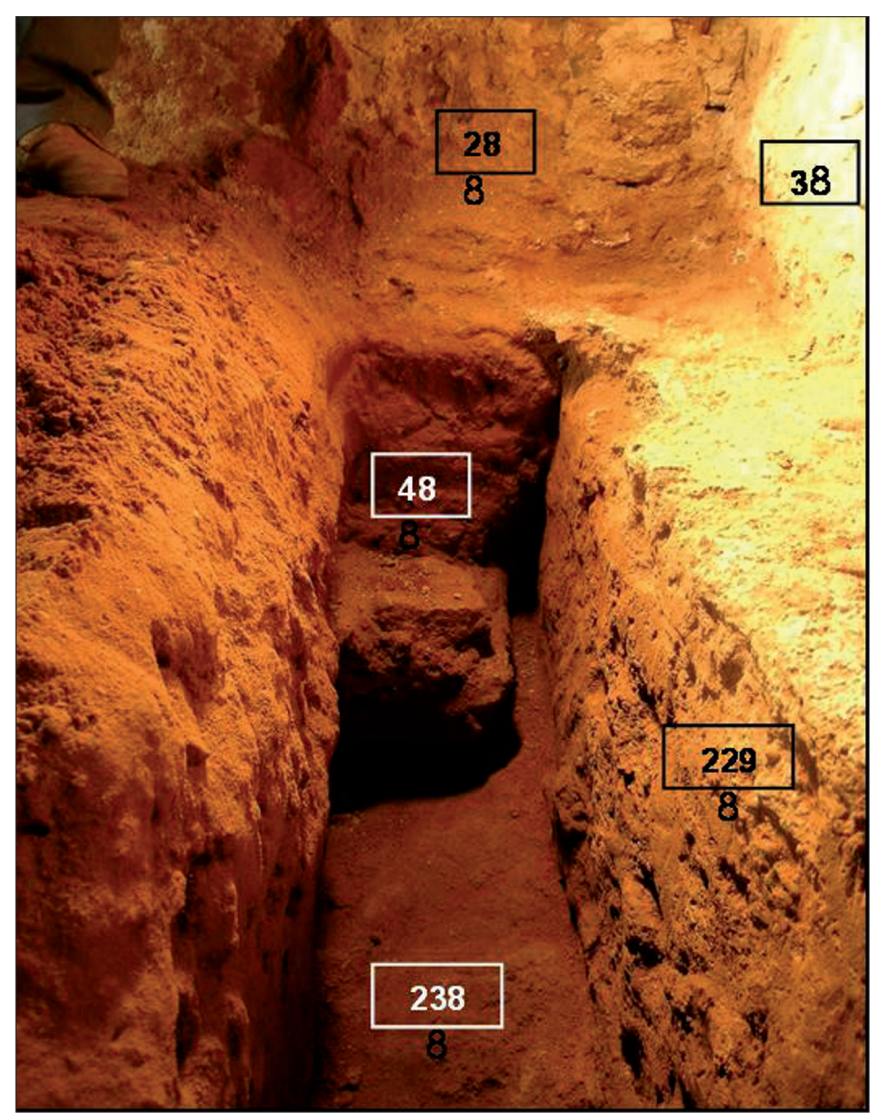

Fig. 16. Zona de contacto por adosamiento simple del muro UE 28 sobre el muro UE 3 cubierta de albardillas ni aspilleras defensivas (Fig. 5). Esta línea de almenas y merlones se conservan en sus cuatro frentes, estando en el alzado Norte y Sur ocultos bajo los merlones de época posterior (Fig. 13). Siguen una disposición regular, con unas medidas de $0,65 \times 0,75 \times 0,50 \mathrm{mts}$. La fábrica es de mampuestos de menor tamaño al igual que todo el parapeto del muro, trabado con mortero de cal de color anaranjado. Los merlones de las esquinas se prolongan ortogonalmente hacia el muro contiguo transversal, formando un doble merlón en «L». La línea de merlones del muro Norte se ve interrumpida en dos zonas, dejando un espacio más amplio de almenado, posiblemente abierto en periodos posteriores tras la incorporación de la artillería como elemento defensivo (Fig. 15).

\section{Actividad II. Rehabilitación y nueva distribución de los espacios}

En Plena Edad Moderna se ejecutaron obras importantes que modificarían tanto su distribución interna como externa. Se construyen los dos muros interiores encastrados a las paredes del Castillo resultando dos naves longitudinales de menor luz que las primitivas. Son muros de mampostería de 0,47 mts. de ancho, conservando parte de su alzado, ya que la planta alta sería reconstruida en fases posteriores. En origen tendrían una altura similar a la actual. Dicha hipótesis deriva de la relación funcional «incompatible» que tienen las cajas de vigas con los vanos de la planta alta. Siendo éstos claramente posteriores a dichos elementos, ya que el lugar que ocupan las vigas afecta directamente a la estructura sustentante de los vanos, que apoyan directamente sobre ellos. En todas las estancias las roscas de los arcos respetan estas cajas de vigas, incluso siendo ambos incompatible. Sería ilógico pensar que ambos elementos, vigas y arcos, fueron construidos a la vez, ya que en este supuesto se habrían ubicado de forma alterna, de manera que ambos sistemas pudieran trabajar a la par correctamente (Figs. 21 y 23).

Por tanto, en estos momentos el espacio interno de la Casa sería semejante al que vemos hoy, dos naves longitudinales Norte-Sur y otras dos transversales de menor tamaño Este-Oeste.

El espacio vertical también sufriría modificaciones. Se dividió la altura del edificio en dos plantas a una cota sobre superficie de 4,40 m, esta altura coincide con la actual (Fig. 21). El nuevo forjado se encastra sobre los muros del castillo anulando los vanos originales. Las cubiertas continuarían a la misma cota, pero dispuestas de manera diferente, apoyando sobre los nuevos muros y los muros transversales a estos dos. La incorporación de este nuevo 

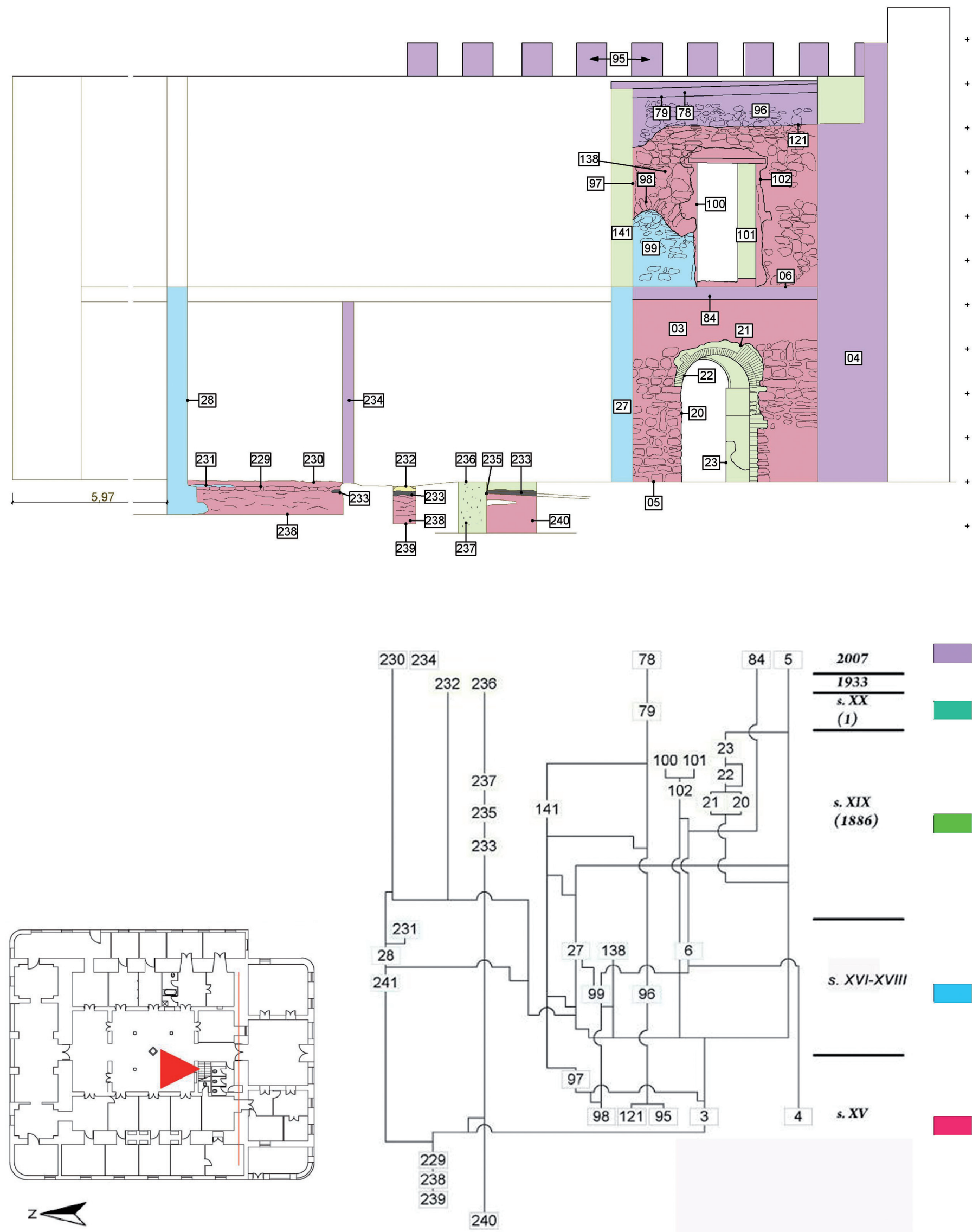

Fig. 17. Estancia 3 y 4, alzado Sur. Análisis estratigráfico 
forjado supuso la amortización del adarve, ya que para que las vigas tuviesen una buena sujeción se recreció todo el paseo de ronda hasta la altura de las almenas (Fig. 11). Las cajas de viga están situadas directamente sobre la línea de adarve quedando protegidas con mampuestos de mayor tamaño (Figs. 21 y 23).

El control de movimientos de tierras nos ha permitido observar la cimentación de uno de los muros longitudinales interiores construidos en este momento (Figs. 16 y 17). Es una zapata continua de aparejo mixto de ladrillos de $0,22 \times 0,03 \mathrm{~m}$ y mampuestos regulares de tamaño medio, bien trabados con mortero de cal. El ancho del escalón de la zapata es de 0,10 mts. con 0,35 $\mathrm{m}$ de profundidad. La cota de uso del nuevo muro respeta la cota de uso del edificio anterior. Se trata de una capa de preparación de cal apisonada situado a 0,10 m. bajo rasante. Tras el control de movimiento de tierras el material cerámico extraído de este lugar, solo un fragmento, pertenece a producciones modernas, del s. XV-XVI.

\section{Actividad III. Construcción del Hotel}

El espacio interior continuó con la misma distribución que la fase anterior, pero con un aumento en el número de tránsitos (Fig. 19). Los muros longitudinales se mantuvieron en planta baja y se reconstruyeron en planta alta. En el alzado oriental puede verse la diferencia de fábricas entre uno y otro piso. La factura de los muros correspondientes a este momento incorpora el ladrillo fino. Son muros de aparejo mixto, de hiladas de ladrillos alternadas irregularmente con mampuestos, cada $0,40 /$ $0,50 \mathrm{~m}$. El módulo latericio es de 0,27 x 0,13 x 0,025/ $0,03 \mathrm{~m}$, con llagas de $0,02 \mathrm{y}$ listeles de apenas $1 \mathrm{~cm}$,

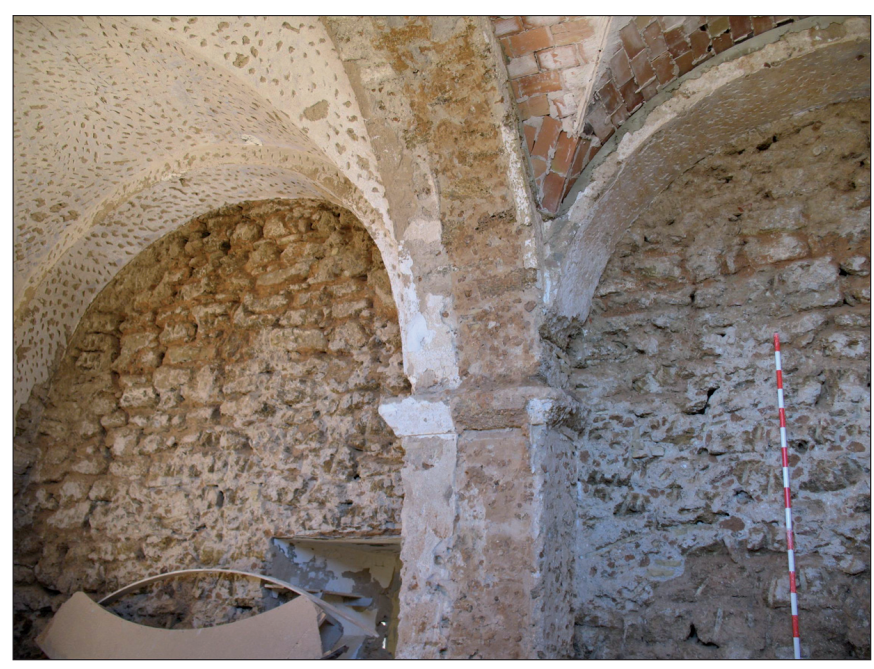

Fig. 18. Galería del mirador Norte. Pilares adosados al muro primitivo UE 1 trabados con mortero de cal. El muro tiene un espesor de $0,49 \mathrm{~m}$. Se sigue empleando el sistema de andamiajes para la construcción de las paredes.

La zona noble del hotel se centra en el mirador sobre un escarpe de mampuestos a modo de cimentación salvando con ello el desnivel del terreno con la línea de pleamar. La planta baja es un espacio porticado divido en cinco tramos cubiertos con bóvedas de aristas apoyadas sobre pilares (Figs. 13 y 18). En planta alta es una terraza descubierta y transitable con acceso desde el piso superior. La construcción del hotel supuso la incorporación de una portada monumental acorde con el nuevo uso (Fig. 12). Se trata de un vano ojival al exterior y escarzado al interior abierto a posteriori, como muestra la interfaz de rotura del muro 1 para la intrusión de ésta. Construido en piedra ostionera, con sillarejos y ladrillos bien trabados con un mortero grisáceo de arena y cal. Es el único vano que aparece en el alzado Norte de la planta baja de la estancia 1 y probablemente donde se encontraría el vano de acceso al edificio en su primer momento constructivo. Presenta mayor irregularidad en su zona Oeste con una refacción amplia de sillarejos y mampuestos en resalte. Tal vez la puerta primitiva estuviese descentrada respecto al eje del muro y para corregir esa asimetría se macizó la jamba occidental, a su vez, esta puerta queda también descentrada respecto a la galería del mirador, fosilizando la asimetría de la posible puerta original (Fig. 21).

Otro de los elementos incorporados en este momento fue la torre, otorgándole verticalidad a un edificio que desde sus orígenes destacaba por su horizontalidad (Figs. 1 y 13). Tiene un cuerpo de planta cuadrada de $4 \mathrm{~m}$ de lado con una altura de $6 \mathrm{~m}$. La zona superior queda rematada por una línea de merlones. Los muros de la torre se apoyan sobre las almenas originales del Castillo.

El control de movimientos de tierras nos ha permitido registrar la cimentación de los muros transversales. Dichos muros son coetáneos, la cerámica extraída de la cimentación fecha a ambos ya en época contemporánea, dentro del s. XIX.

Todos los vanos que comunican los espacios interiores pertenecerían a esta fase. Se trata de puertas abocinadas rematadas por arcos de medio punto rebajados, también abocinados. Las jambas de las puertas están reforzadas con ladrillos que traban con la fábrica del muro. Los vanos son del tipo tabicado a la catalana con dos hiladas de ladrillo. A diferencia de las jambas, los arcos están trabados con mortero de cal de color grisáceo.

En el momento de la construcción del hotel el forjado superior se continúan usando, como evidencian las huellas 

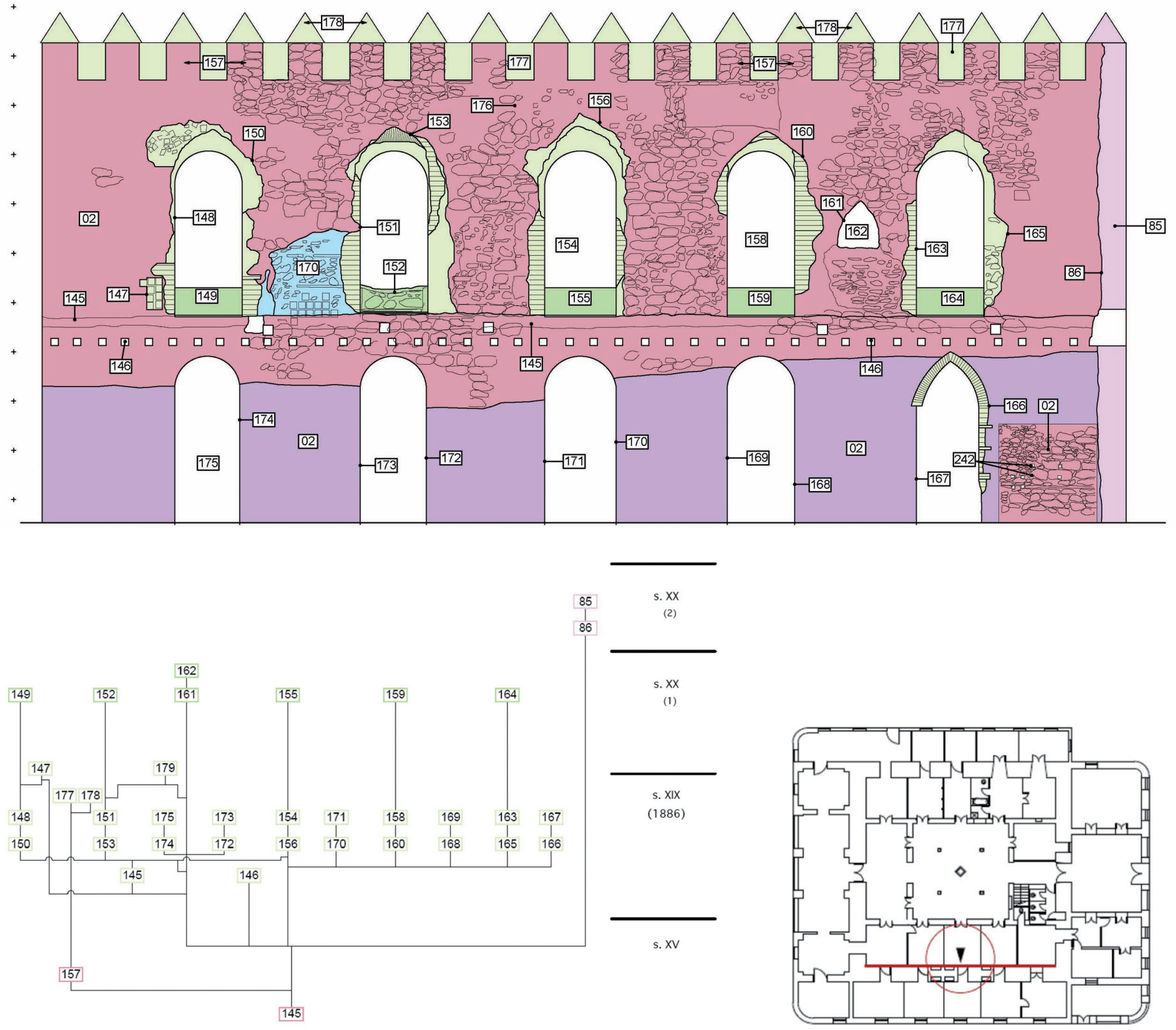

Fig. 19. Estancia 6, alzado Oeste. Análisis estratigráfico

dejadas en el alzado Sur-estancia 1 y el respeto hacia las huellas del forjado en el alzado Norte-estancia 1. Este forjado se eliminaría en fases posteriores y se elevaría en altura tal como lo vemos hoy.

\section{Actividad IV. Reparaciones y subida de forjados}

La principal obra fue la elevación de las cubiertas. Se alivió toda la zona alta eliminado la anterior cubierta de vigas y se colocó un nuevo forjado de viguetas sobre el antiguo, quedando la planta alta con una altura de 4,10 m. También se elevó el pavimento de la azotea del mirador, provocando la subida de cotas de la escalera de acceso a él.

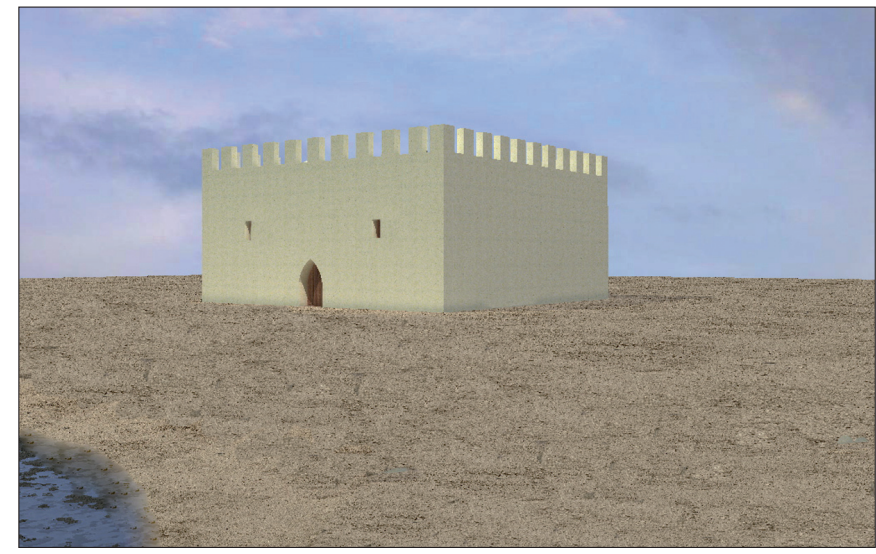

Fig. 20. Reconstrucción virtual de la Actividad I 

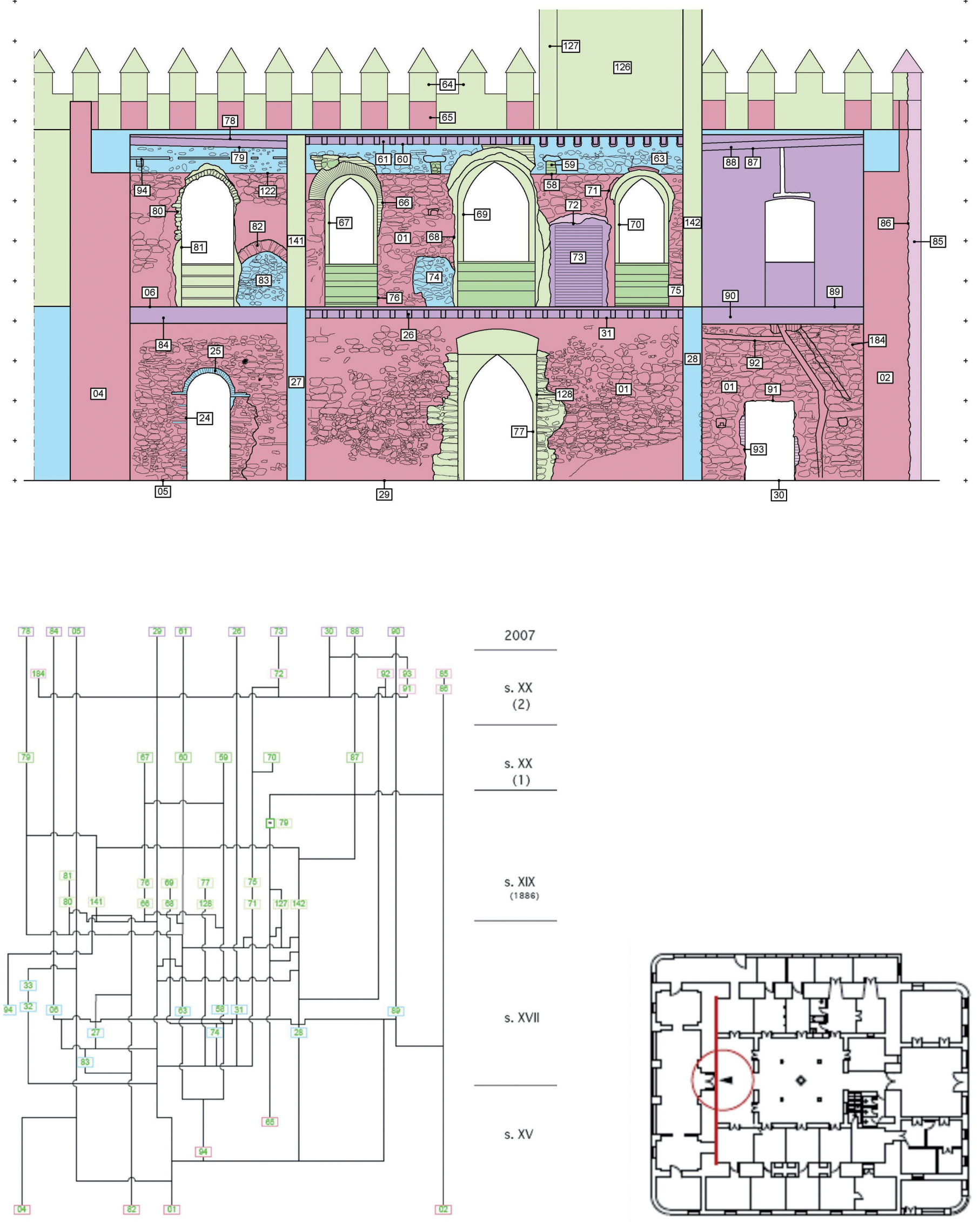

Fig. 21. Estancia 1, 2, 4, alzado Sur. Análisis estratigráfico 


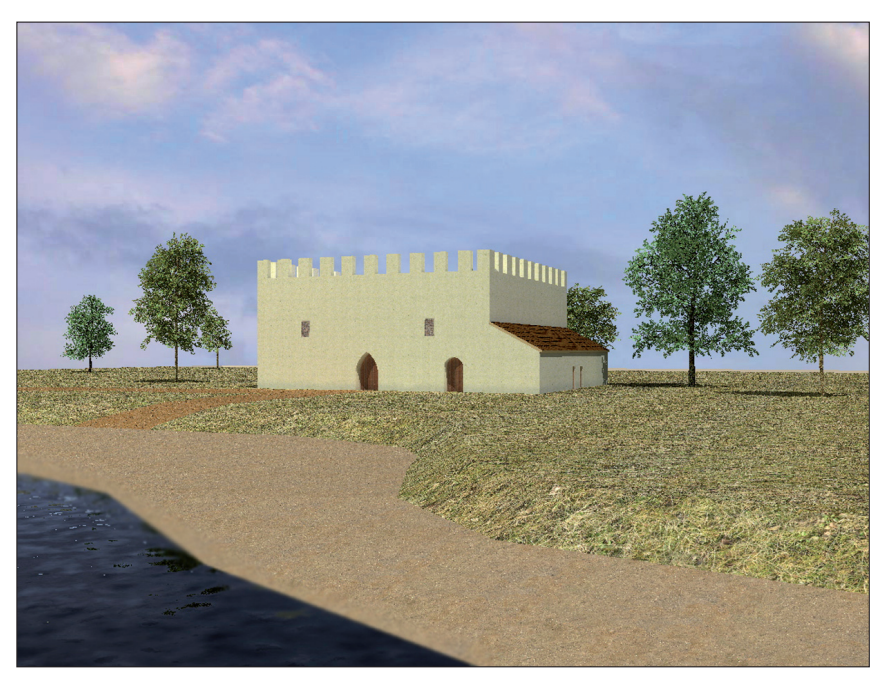

Fig. 22. Reconstrucción virtual de la Actividad II

\section{Actividad V. Reparaciones contemporáneas del hotel}

El material empleado, cemento Pórtland y ladrillo de gafa, delatan una fecha muy avanzada. Hay necesidad por ganar espacio para zonas de almacenamiento. Se hacen taquillas y roperos empotrados en diferentes puntos del edificio, perforando los muros primitivos. En estas fechas también se modificaría el sistema de saneamiento del hotel. Se instalan tuberías de fibrocemento que evacuan las aguas a la red exterior.

\section{Actividad VI. Obra de rehabilitación actual}

Las obras de rehabilitación efectuadas en el 2007 tuvieron un carácter integral. Se cambiaron los forjados de madera, casi inexistentes, por otros nuevos de madera tratada ocupando el mismo lugar que los antiguos. Se eliminó la solería del hotel, de mármol y losas hidráulicas y se sustituyó por placas de granito. Los paramentos, una vez descarnados, se forraron con una malla y mortero proyectado. Se dejaron una serie de testigos desprovistos de recubrimiento, al igual que los vanos originales del castillo para así proceder a su correcta visualización. Se ha eliminado el estilo neogótico del edificio sustituyendo los arcos apuntados por arcos de medio punto.

\section{CONCLUSIONES}

Se tiente constancia de la existencia de restos constructivos previos de los que no se conserva ninguna estructura en alzado tan sólo el fragmento de sillar localizado en el perfil del hueco del ascensor. Especulamos, a falta de una excavación arqueológica, sobre la posibilidad de que perteneciesen a una posible torre almenara-almadraba, relacio- nada tal vez con la que aluden los textos por parte de Guzmán el Bueno en el s. XIII o incluso anterior. Hay que añadir que la inexistencia de huellas de muros transversales originales que distribuyeran el interior del Castillo obliga a que se sirviese de otra estructura portante posiblemente una torre central. Pero la nimiedad del registro subyacente nos imposibilita ir más allá, ni tan siquiera podemos aseverar que el nivel de amortización del sillar sea el mismo que las arenas cortadas por la cimentación del Castillo, en cuyo caso queda desestimada por completo la hipótesis de una torre previa perviviendo con el Castillo.

Ante la falta de sondeos arqueológicos y con fuentes documentales dudosas (tradicionalmente se tenían por válidas aquellas que identificaban la autoría del Castillo de manos de Guzmán el Bueno en el s. XIII) para la datación de la Actividad I nos hemos basado fundamentalmente en las relaciones estratigráficas, las características formales del edificio y la recogida de un fragmento cerámico del s. XV hallado en el interior de un mechinal del muro Norte. Con todo ello especulamos con una fecha más tardía que la señalada por las fuentes (s. XIII) retardando posiblemente sus orígenes al s. XV.

En esta época se dieron una serie de acontecimientos importantes en la villa: En 1477 se redactó la Carta Puebla de Chipiona repoblándola con 700 familias. Hay documentos que apuntan a una fecha más temprana para la construcción original de la Iglesia de la $\mathrm{O}$, a mediados del s. XV. Fue un momento donde pudieron realizarse a su vez otro tipo de obras civiles como el Castillo.

A este periodo corresponden los cuatro muros perimetrales del Castillo configurando un edificio de planta cuadrada ausente de torres o resaltes, con alzados similares a los de la vecina Torre de Doña Blanca del Puerto de Santa María (Cádiz), fechada en el s. XV. Tanto por su funcionalidad como por su tipología formal hemos relacionado al Castillo de Chipiona con el tipo de construcción defensiva denominada "Casa-Fuerte o Casa-Torre». Estos edificios responden a una tipología constructiva generalizada en el Norte de España, principalmente en la zona centro, de origen bajomedieval (XIV-XV) pero de uso extendido hasta bien entrada la modernidad. Se trata de un edificio fortificado de uso residencial pero con funciones de apropiación, control, administración y defensa del territorio a cargo del señor de la Casa y gobernante de la Villa ${ }^{19}$. El hecho de equiparar al Castillo de Chipiona con estos edificios no desestima su identificación como Castillo al tratarse de un edificio fortificado con paseo de ronda

\footnotetext{
${ }^{19}$ Azkarate Garai-Olaun y García Gómez, 2004: 9.
} 

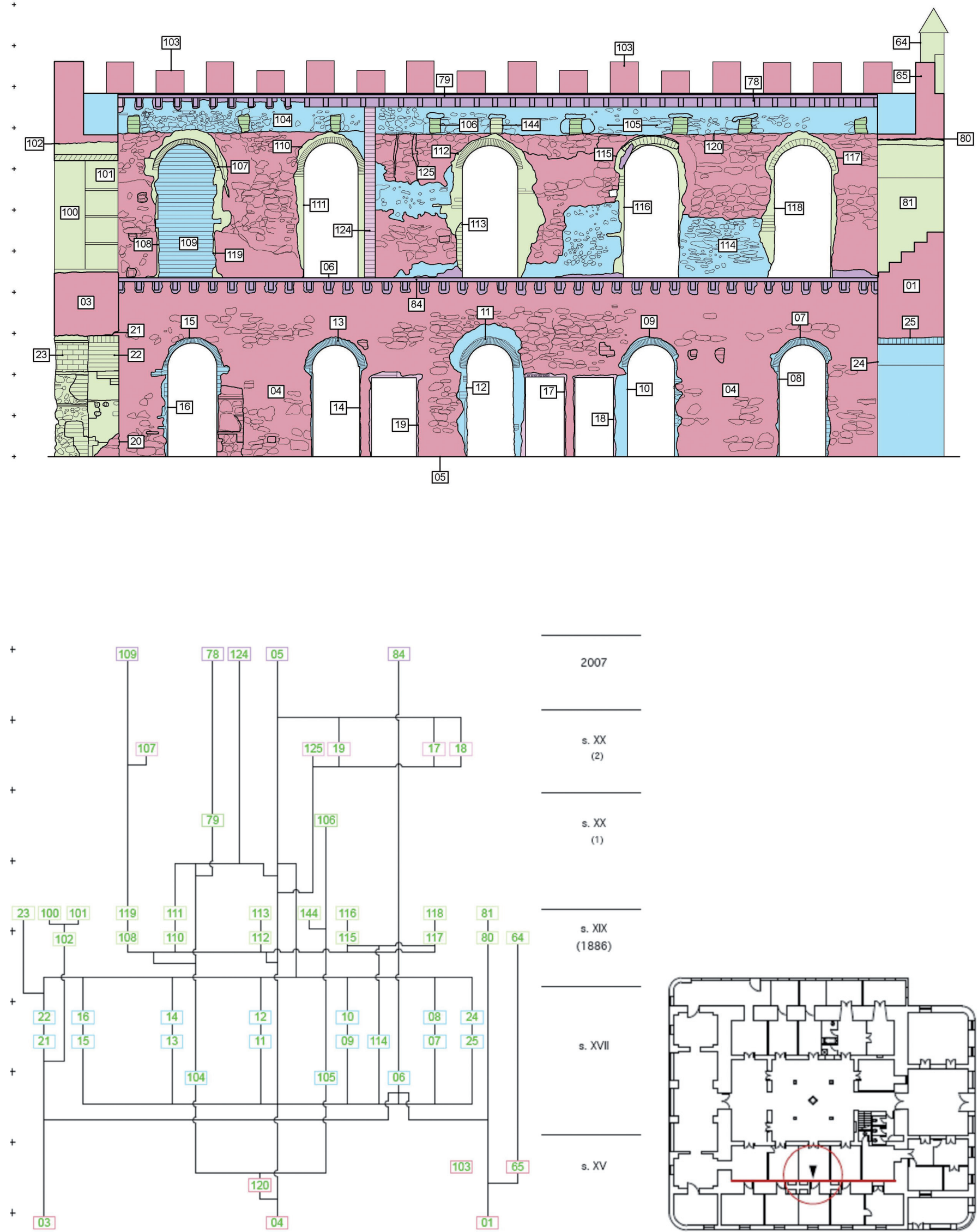

Fig. 23. Estancia 4, alzado Oeste. Análisis estratigráfico 


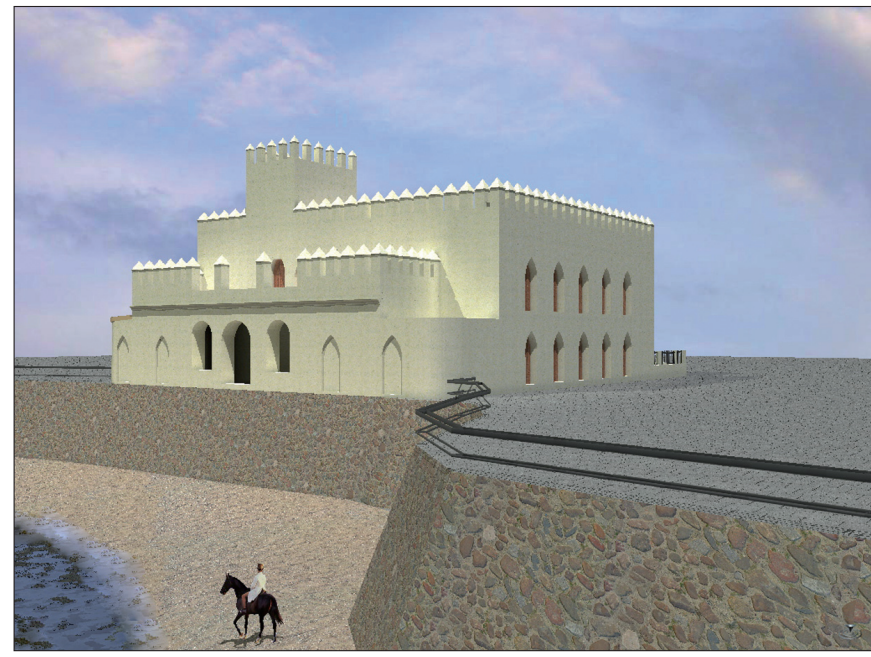

Fig. 24. Reconstrucción virtual de la Actividad III

rematado por almenas, pero por el contrario carece de elementos poliorcéticos propios a él como son torres, barbacanas, fosos, plaza de armas o murallas. De la misma manera su funcionalidad también lo asemejan a esas construcciones del Norte de España, se trataba de edificios autosuficientes, la vivienda fortificada del señor de la villa. Pero sobre todo eran un centro de coordinación productiva que controlaba los pasos claves de las rutas comerciales ${ }^{20} \mathrm{de}$ la misma manera que el Castillo de Chipiona controlaba la ruta comercial de acceso por el Guadalquivir.

Teorizamos con la posibilidad de que la construcción del Castillo de Chipiona se hiciese sobre una construcción previa ¿̇torre almenara?, bien cubriéndola perimetralmente y aprovechando parte de sus estructuras para su organización interna, en el caso de que se hubiesen conservado sus alzados, bien edificando el Castillo de nueva planta sobre los cimientos de la anterior.

El Castillo es un edificio de planta cuadrada a una sola altura. La distribución interna es diferente a la actual, con naves laterales más anchas iluminadas por vanos apuntados. La presencia de estas ventanas descarta la posibilidad de que los cuatro muros perimetrales correspondiesen a una muralla almenada que protegiese un espacio interior y no a un edificio. No han aparecido huellas de forjado a media altura lo que nos indica que no hubo un doble nivel. Tampoco se han localizado indicios de encastres o adosamientos en estos muros que atestigüen la presencia de muros que distribuyesen el interior del edificio, apoyando con ello la teoría sobre la presencia de una estructura central potente ¿̇orre? sobre la que se acoplarían el resto de elementos internos.

${ }^{20}$ Ib. 16.
Según el cuadro conservado en la ermita del Cristo de las Misericordias, el castillo en 1755 poseía un revellín adosado a la fachada Norte protegiendo el acceso al edificio desde este lugar. Tras el estudio de alzados, en el muro Sur no se han detectado huellas que nos indiquen la presencia de ninguno de estos elementos, revellín y puerta original. A pesar de ello el vano de mayor envergadura del edificio se encuentra en ese lugar, posiblemente modificando el anterior de menor tamaño, por lo que cabe la posibilidad de que la puerta de acceso principal se encontrase ubicada en esta zona.

La datación de la Actividad II la justificamos en la relación de antero-posterioridad que tienen los elementos ubicándola dentro de un arco cronológico amplio que abarca desde el s. XVI hasta el XVIII. Es decir, se trata de una actividad posterior a la construcción original del Castillo pero previo a la reestructuración definitiva del mismo en hotel. Por tanto, y ante la falta de sondeos arqueológicos que hubiesen aportado una información cronológica y formal más precisa, tomamos con reserva la época moderna para la segunda intervención constructiva desarrollada en el edificio.

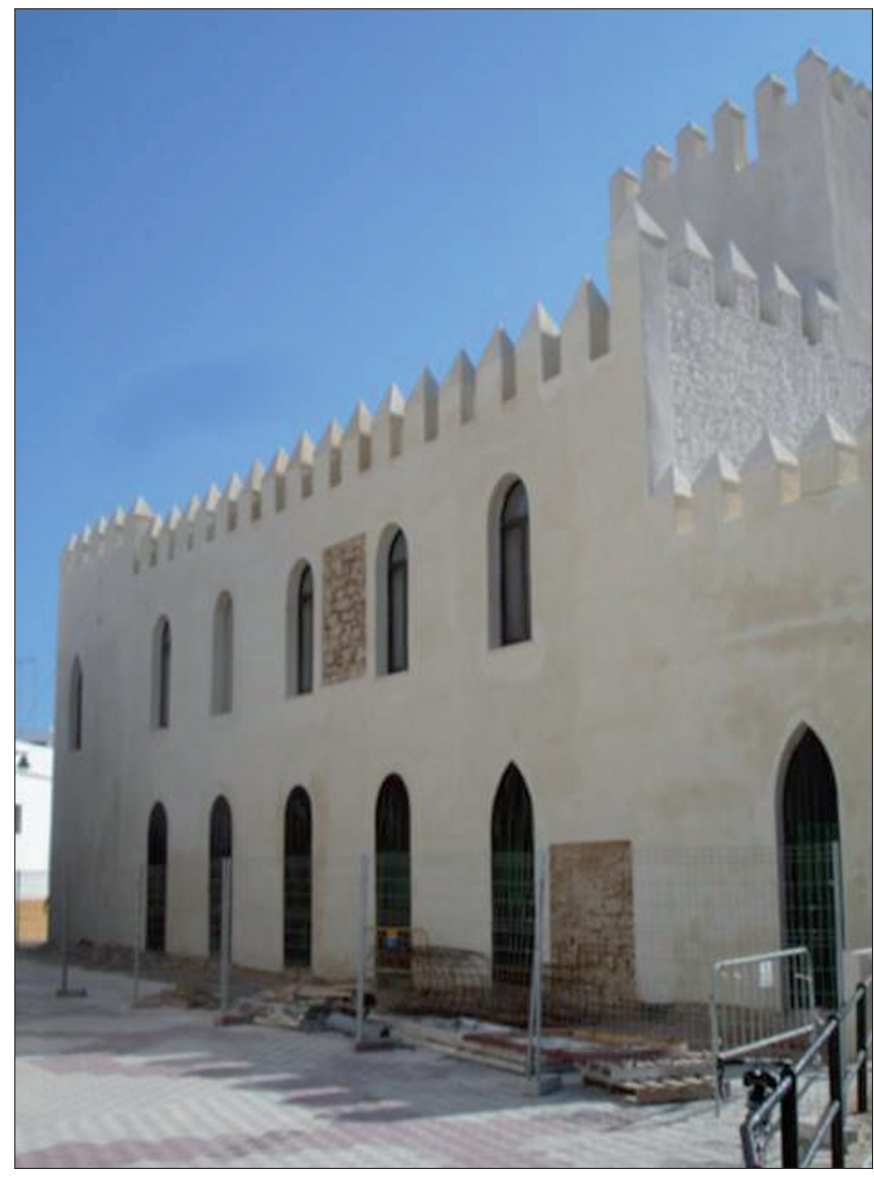

Fig. 25. Exterior del edificio tras la restauración de 2007. Fachada Este 


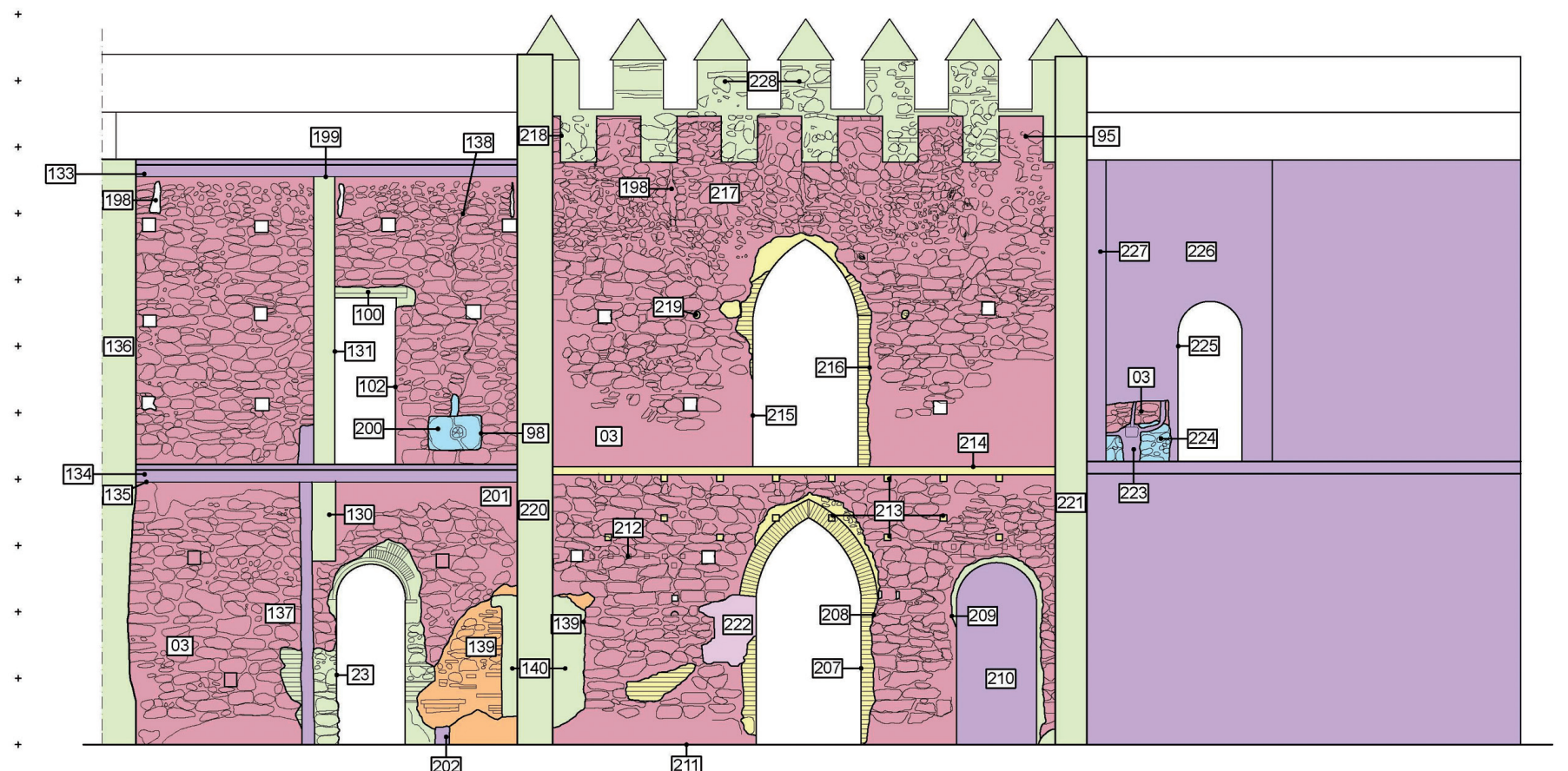

202
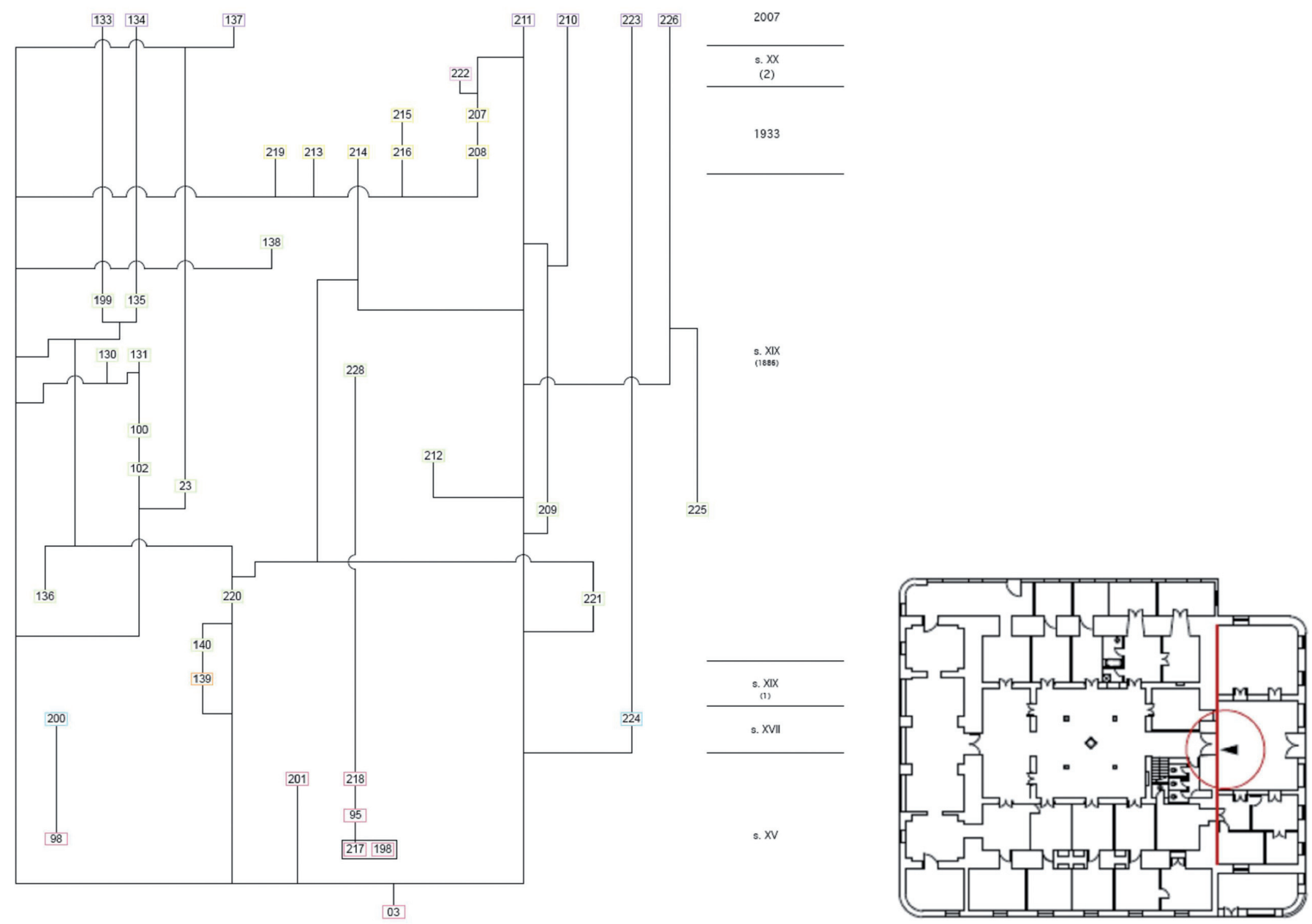

Fig. 26. Estancia 7, alzado Norte. Análisis estratigráfico 
Cuando las crónicas se refieren a la fortaleza lo hacen como edificio en ruinas. Sobre todo sería en el s. XVII cuando la villa sufriría una de sus etapas más criticas, encontrándose desprotegidas ante los ataques marinos y con pocos recursos defensivos y económicos. Era necesario la reconstrucción del Castillo para hacerlo habitable y a la vez seguro en caso de ataque. En el s. XVIII se convirtió en prisión local, en las actas capitulares se refieren a él como cárcel pública de la villa.

El resultado de las obras dio lugar a la división de los espacios. Se coloca un forjado a media altura pasando a ser un edificio de dos plantas, se abren vanos en planta baja y se añade una nave en el lateral Oeste. Estas reformas afectaron en mayor medida al sector occidental.

La anulación del adarve como elemento defensivo implica un cambio en las técnicas de combate. La subida de cota hasta la línea de almenas adecuaría la terraza para el uso de cañones, sistema defensivo propio del momento. La poca altura del edificio hacía que fuera idóneo para la ofensiva costera, ya que de esta manera podían atacar con la técnica del tiro con cañón rasante. La eliminación de dos de los merlones del frente Norte, bien desmontados a conciencia o bien derruidos, pero nunca reconstruidos hasta la construcción del hotel, facilitaría la maniobrabilidad de la artillería pesada.

El último uso que tuvo el Castillo y fruto de su imagen actual derivó de su adaptación al uso hotelero identificado con la Actividad III. La primera referencia conocida que hace mención del Castillo como hotel aparece en un acta capitular de 1887, donde Doña Manuela Fernández Salamanca de la Bastida pide que se amillare una casa hotel «el Castillo» a su nombre. A esta fase corresponden las transformaciones más drásticas realizadas en el edificio. El nuevo uso dio lugar a una compartimentación total de los espacios ampliando la planta del edificio primitivo y fraccionando su interior en pequeñas alcobas. Se perforaron los cuatro frentes del castillo con multitud de vanos ojivales que desvirtuaron la realidad del edificio primigenio. Esta inclinación historicista afectó también a la zona de almenas que se cubrieron con albardillas a cuatro aguas, además de la erección de la torre.

Desde 1922 veranean en el Castillo Don Carlos de Borbón y D. ${ }^{a}$ Luisa de Orleáns. Seguramente este sería uno de los motivos por los que se efectuaron una serie de obras de adecentamiento del hotel. Para ello se alivió la planta alta elevando su forjado.

\section{Bibliografía}

Alarcón Castellano, F. J.: Intervención arqueológica de emergencia Avda. de Sevilla, $n^{o}$ 2. Chipiona (Cádiz). Anuario Arqueológico de Andalucía 1991. Vol. III. Pp. 51-57.

Antón Solé, P.: Historia medieval de Cádiz y su provincia a través de sus Castillos. Instituto de Estudios Gaditanos, 1976.

Azkarate Garai-Olaun, A., García Gómez, I.: Las casas-torre bajomedievales. Análisis sistémico de un proceso de reestructuración espacial/territorial. Arqueología de la Arquitectura 3, 2004. Pp. 7-37.

Barros Caneda, J. R.: Castillos de Cádiz. Cádiz, 2004.

Barrantes Maldonado, A.: Ilustraciones de la Casa de Niebla. Memorial Histórico Español, Vols. 9 y 10. Madrid, 1857.

Carmona Bohórquez, D. (Fr.): Historia Sacra de Nuestra Señora de Regla y de sus maravillosas obras. 1639. Manuscrito R.- 1177. Biblioteca Nacional.

Estrabón: Geografía. Libros III-IV. Traducciones, introducciones y notas de Ma José Meana y Félix Piñero. Madrid, 1992.

García Vargas, E., Ramos Millán, A., et alii.: La carta de riesgo arqueológico de la alfarería romana de el Olivar de Chipiona (Cádiz). La actuación de urgencia de 2001 como gestión preventiva. Anuario Arqueológico de Andalucía 2001. Vol. III. Pp. 49-62.

Garrido Castro, P. M.: Proyecto de Rehabilitación del Castillo de Chipiona. Proyecto fin de Carrera. 2001-2002, Escuela Universitaria de Arquitectura Técnica de la Universidad de Sevilla. Inédito.

Higueras-Milena Castellano, J. M.: Cautela Arqueológica del dragado de restitución de calados del puerto de Chipiona. Cádiz. Anuario Arqueológico de Andalucía 1998. Vol. III. Pp. 55-57.

Mellado Rodríguez, J., Naval Molero J. L.: Chipiona siglo XVII. Actas Judiciales. $n^{\circ}$ I. Febrero 1997. Asociación Cultural Caepionis.

Mellado Rodríguez, J., Naval Molero J. L., Herrero, González, E.: Chipiona siglo XVII. Actas Judiciales. no II. Febrero 1998. Asociación Cultural Caepionis.

Naval Molero J. L.: El Castillo de Chipiona. Crónicas de Chipiona.

Ramos Millán, A., Riesco García, J. C.: La villa romana de Las Canteras (Chipiona, Cádiz). Procesos formativos y transformativos del registro arqueológico $e$ inferencias preliminares del asentamiento. Cuadernos de prehistoria de la Universidad de Granada, no 8. Granada, 1983.

Rodríguez-Piñero Bravo-Ferrer, J.: Cádiz y su provincia. Sevilla, 1984-1985.

Romero De Torres, E.: Provincia de Cádiz (1908-1909). Catálogo monumental de España. Madrid, 1934.

Ruano Fernández, F.: Chipiona. Los Pueblos de la Provincia de Cádiz, n 16. Cádiz, 1985.

Ruíz Aguilar, S.: Cautela Arqueológica realizada en la ampliación del abrigo del puerto de Chipiona (Cádiz). Anuario Arqueológico de Andalucía 1997. Vol. III. Pp. 57-59.

Schulten, A.: Tartessos. Huellas del Pasado. Historia y Arqueología. Traducción del alemán por Manuel García Morente. Sevilla, 2006.

Tabales Rodríguez, M. A.: Sistemas de Análisis Arqueológico de edificios históricos. Sevilla, 2002.

V.V.A.A.: Chipiona en el recuerdo. Chipiona, 1995.

Recibido: 15 de septiembre de 2010

Aceptado: 27 de noviembre de 2010 